\title{
1 The SARS-CoV-2 conserved macrodomain is a mono-ADP-ribosylhydrolase
}

2

Yousef M.O. Alhammad ${ }^{\mathrm{a}}$, Maithri M. Kashipathy ${ }^{\mathrm{b}}$, Anuradha Roy ${ }^{\mathrm{c}}$, Jean-Philippe Gagnéd,e, Peter McDonald ${ }^{\mathrm{c}}$, Philip Gao ${ }^{\mathrm{f}}$, Louis Nonfoux ${ }^{\mathrm{d}, \mathrm{e}}$, Kevin P. Battaile ${ }^{\mathrm{g}}$, David K. Johnson ${ }^{\mathrm{h}}$, Erik D. Holmstrom $^{\mathrm{a}}$, Guy G. Poirier ${ }^{\mathrm{d}, \mathrm{e}}$, Scott Lovell ${ }^{\mathrm{b}}$ and Anthony R. Fehr ${ }^{\mathrm{a}, \#}$

aDepartment of Molecular Biosciences, University of Kansas, Lawrence, Kansas 66045, USA bProtein Structure Laboratory, University of Kansas, Lawrence, Kansas 66047, USA

'High Throughput Screening Laboratory, University of Kansas, Lawrence, Kansas 66047, USA ${ }^{\mathrm{d}}$ Department of Molecular Biology, Medical Biochemistry and Pathology, Laval University Cancer Research Center, Québec City, QC, G1V 0A6, Canada ${ }^{\circ} \mathrm{CHU}$ de Québec Research Center, CHUL Pavilion, Oncology Division, Québec City, QC, G1V 4G2, Canada

Protein Production Group, University of Kansas, Lawrence, Kansas 66047, USA

gNYX, New York Structural Biology Center, Upton, NY 11973, USA

${ }^{\mathrm{h}}$ Molecular Graphics and Modeling Laboratory and the Computational Chemical Biology Core, University of Kansas, Lawrence, Kansas 66047, USA

\#Correspondence: arfehr@ku.edu; Tel.: +1- (785) 864-6626 (K.S.)

Running title: SARS-CoV-2 Mac1 removes ADP-ribose from protein

Keywords: Coronavirus, SARS-CoV-2, macrodomain, ADP-ribose, poly-ADP-ribose, 


\section{ABSTRACT}

24 Severe acute respiratory syndrome coronavirus 2 (SARS-CoV-2) and other SARS-like-CoVs

25 encode 3 tandem macrodomains within non-structural protein 3 (nsp3). The first macrodomain,

$26 \mathrm{Mac1}$, is conserved throughout CoVs, and binds to and hydrolyzes mono-ADP-ribose (MAR)

27 from target proteins. Mac1 likely counters host-mediated anti-viral ADP-ribosylation, a

28 posttranslational modification that is part of the host response to viral infections. Mac1 is

29 essential for pathogenesis in multiple animal models of $\mathrm{CoV}$ infection, implicating it as a

30 virulence factor and potential therapeutic target. Here we report the crystal structure of SARS-

31 CoV-2 Mac1 in complex with ADP-ribose. SARS-CoV-2, SARS-CoV and MERS-CoV Mac1

32 exhibit similar structural folds and all 3 proteins bound to ADP-ribose with low $\mu \mathrm{M}$ affinities.

33 Importantly, using ADP-ribose detecting binding reagents in both a gel-based assay and novel

34 ELISA assays, we demonstrated de-MARylating activity for all $3 \mathrm{CoV}$ Mac1 proteins, with the

35 SARS-CoV-2 Mac1 protein leading to a more rapid loss of substrate compared to the others. In

36 addition, none of these enzymes could hydrolyze poly-ADP-ribose. We conclude that the SARS-

37 CoV-2 and other CoV Mac1 proteins are MAR-hydrolases with similar functions, indicating that

38 compounds targeting CoV Mac1 proteins may have broad anti-CoV activity. 


\section{IMPORTANCE}

41 SARS-CoV-2 has recently emerged into the human population and has led to a worldwide

42 pandemic of COVID-19 that has caused greater than 900 thousand deaths worldwide. With, no

43 currently approved treatments, novel therapeutic strategies are desperately needed. All

44 coronaviruses encode for a highly conserved macrodomain (Mac1) that binds to and removes

45 ADP-ribose adducts from proteins in a dynamic post-translational process increasingly

46 recognized as an important factor that regulates viral infection. The macrodomain is essential for

$47 \mathrm{CoV}$ pathogenesis and may be a novel therapeutic target. Thus, understanding its biochemistry

48 and enzyme activity are critical first steps for these efforts. Here we report the crystal structure of

49 SARS-CoV-2 Mac1 in complex with ADP-ribose, and describe its ADP-ribose binding and

50 hydrolysis activities in direct comparison to SARS-CoV and MERS-CoV Mac1 proteins. These

51 results are an important first step for the design and testing of potential therapies targeting this

52 unique protein domain. 


\section{INTRODUCTION}

The recently emerged pandemic outbreak of COVID-19 is caused by a novel coronavirus named severe acute respiratory syndrome coronavirus 2 (SARS-CoV-2) (1,2). As of September

5716,2020 , this virus has been responsible for $\sim 30$ million cases of COVID-19 and $>900,000$

58 deaths worldwide. SARS-CoV-2 is a member of the lineage B $\beta-\mathrm{CoVs}$ with overall high

59 sequence similarity with other SARS-like CoVs, including SARS-CoV. While most of the

60 genome is $>80 \%$ similar with SARS-CoV, there are regions where amino acid conservation is

61 significantly lower. As expected, the most divergent proteins in the SARS-CoV-2 genome from

62 SARS-CoV include the Spike glycoprotein and several accessory proteins including $8 \mathrm{a}$ (absent),

$638 \mathrm{~b}$ (extended), and $3 \mathrm{~b}$ (truncated). However, somewhat unexpectedly, several non-structural

64 proteins also show significant divergence from SARS-CoV, including non-structural proteins 3,

654 , and 7, which could affect the biology of SARS-CoV-2 $(3,4)$.

Coronaviruses encode 16 non-structural proteins that are translated from two open

67 reading frames (ORFs), replicase 1a and 1ab (rep1a and rep1ab) (5). The largest non-structural

68 protein is the non-structural protein 3 (nsp3) that encodes for multiple modular protein domains.

69 These domains in SARS-CoV-2 diverge in amino acid sequence from SARS-CoV as much as

$7030 \%$, and SARS-CoV-2 nsp3 includes a large insertion of 25-41 residues just upstream of the

71 first of three tandem macrodomains (Mac1, Mac2, and Mac3) (Fig. 1A) (3). In addition to this

72 insertion, the individual macrodomains show large amounts of amino acid divergence. Mac1

73 diverges 28\% from SARS-CoV and 59\% from MERS-CoV, while Mac2 and Mac3 diverge 24\%

74 from SARS-CoV. It is feasible that these significant sequence differences could impact the

75 unique biology of SARS-CoV-2. However, macrodomains have a highly conserved structure,

76 and thus sequence divergence may have little impact on their overall function. Mac1 is present in 
77 all CoVs, unlike Mac2 and Mac3, and early structural and biochemical data demonstrated that it

78 contains a conserved three-layered $\alpha / \beta / \alpha$ fold and binds to mono-ADP-ribose (MAR) and other

79 related molecules (6-10). This is unlike Mac2 and Mac3, which fail to bind ADP-ribose and

80 instead appear to bind to nucleic acids $(11,12)$. ADP-ribose is buried in a hydrophobic cleft of

81 Mac1 where the ADP-ribose binds to several highly-conserved residues such as aspartic acid at

82 position 23 (D23) and asparagine at position 41 (N41) of SARS-CoV (Fig. 1B) (6). Mac1

83 homologs are also found in alphaviruses, Hepatitis E virus, and Rubella virus, and structural

84 analysis of these macrodomains have demonstrated that they are very similar to CoV Mac1 (13,

85 14). All are members of the larger MacroD-type macrodomain family, which includes human

86 macrodomains Mdo1 and Mdo2 (15).

87 The CoV Mac1 was originally named ADP-ribose-1"-phosphatase (ADRP) based on data

88 demonstrating that it could remove the phosphate group from ADP-ribose-1"-phosphate (6-8).

89 However, the activity was rather modest, and it was unclear why this would impact a virus

90 infection. More recently it has been demonstrated that $\mathrm{CoV}$ Macl can hydrolyze the bond

91 between amino acid chains and ADP-ribose molecules (16-18), indicating that it can reverse

92 protein ADP-ribosylation $(6,8)$. ADP-ribosylation is a post-translational modification catalyzed

93 by ADP-ribosyltransferases (ARTs, also known as PARPs) through transferring an ADP-ribose

94 moiety from $\mathrm{NAD}^{+}$onto target proteins (19). The ADP-ribose is transferred as a single unit of

95 MAR, or single units of MAR are transferred consecutively to form a PAR chain. Several Mac1

96 proteins have been shown to hydrolyze MAR, but have minimal activity towards PAR $(16,17)$.

97 Several MARylating PARPs are induced by interferon (IFN) and are known to inhibit virus

98 replication, implicating MARylation in the host-response to infection (20). 
Several reports have addressed the role of Mac1 on the replication and pathogenesis of

100 CoVs, mostly using the mutation of a highly conserved asparagine to alanine (N41A-SARS-

$101 \mathrm{CoV}$ ). This mutation abolished the MAR-hydrolase activity of SARS-CoV Mac1 (18). This

102 mutation has minimal effects on $\mathrm{CoV}$ replication in transformed cells, but reduces viral load,

103 leads to enhanced IFN production, and strongly attenuates both murine hepatitis virus (MHV)

104 and SARS-CoV in mouse models of infection $(7,18,21,22)$. MHV Mac1 was also required for

105 efficient replication in primary macrophages, which could be partially rescued by the PARP

106 inhibitors XAV-939 and 3-AB or siRNA knockdown of PARP12 or PARP14 (23). These data

107 suggest that Mac1's likely function is to counter PARP-mediated anti-viral ADP-ribosylation

108 (24). Mutations in the alphavirus and HEV macrodomain also have substantial phenotypic

109 effects on virus replication and pathogenesis $(16,25-28)$. As viral macrodomains are clearly

110 important virulence factors, they are considered to be potential targets for anti-viral therapeutics

Based on the close structural similarities between viral macrodomains, we hypothesized

113 that SARS-CoV-2 Mac1 has similar binding and hydrolysis activity as other CoV Mac1

114 enzymes. In this study, we determined the crystal structure of the SARS-CoV-2 Mac1 protein

115 bound to ADP-ribose. Binding to and hydrolysis of MAR was tested and directly compared to a

116 human macrodomain (Mdo2) and the SARS-CoV and MERS-CoV Mac1 proteins by several in

117 vitro assays. All CoV Mac1 proteins bound to MAR and could remove MAR from a protein

118 substrate. However, the initial rate associated with the loss of substrate was largest for the

119 SARS-CoV-2 Mac1 protein, especially under multi-turnover conditions. In addition, none of

120 these enzymes could remove PAR from a protein substrate. These results indicate that Mac 1 
bioRxiv preprint doi: https://doi.org/10.1101/2020.05.11.089375; this version posted October 28, 2020. The copyright holder for this preprint (which was not certified by peer review) is the author/funder, who has granted bioRxiv a license to display the preprint in perpetuity. It is made available under aCC-BY-NC-ND 4.0 International license.

121 protein domains likely have similar functions, and will be instrumental in the design and testing

122 of novel therapeutic agents targeting the CoV Mac1 protein domain.

123 


\section{RESULTS}

125 Structure of the SARS-CoV-2 Mac1 complexed with ADP-ribose. To create recombinant

126 SARS-CoV-2 Mac1 for structure determination and enzyme assays, nucleotides 3348-3872 of

127 SARS-CoV-2 isolate Wuhan-hu-1 (accession number NC_045512), representing amino acids

128 I1023-K1 197 of rep1a, were cloned into a bacterial expression vector containing an N-terminal

129 6X-His tag and TEV cleavage site. We obtained large amounts $(>100 \mathrm{mg})$ of purified

130 recombinant protein (Fig. S1A). A small amount of this protein was digested by the TEV

131 protease to obtain protein devoid of any extra tags for crystallization and used to obtain crystals

132 from which the structure was determined (Fig. S1B). Our crystallization experiments resulted in

133 the same crystal form (needle clusters) from several conditions, but only when ADP-ribose was

134 added to the protein. This represents an additional crystal form $\left(P 2_{1}\right)$ amongst the recently

135 determined SARS-CoV-2 macrodomain structures (29-31).

136 The structure of SARS-CoV-2 Mac1 complexed with ADP-ribose was obtained using X-

137 ray diffraction data to $2.2 \AA$ resolution and contained four molecules in the asymmetric unit that

138 were nearly identical. The polypeptide chains could be traced from V3-M171 for subunits A/C

139 and V3-K172 for subunits B/D. Superposition of subunits B-D onto subunit A (169 residues

140 aligned) yielded RMSD deviations of $0.17 \AA, 0.17 \AA$ and $0.18 \AA$ respectively between $\mathrm{C} \alpha$ atoms.

141 As such, subunit A was used for the majority of the structure analysis described herein. The

142 SARS-CoV-2 Mac1 protein adopted a fold consistent with the MacroD sub-family of

143 macrodomains that contains a core composed of a mixed arrangement of $7 \beta$-sheets (parallel and

144 antiparallel) that are flanked by $6 \alpha$-helices (Fig. 2A-B).

145 As mentioned above, apo crystals were never observed for our construct, though the apo

146 structure has been solved by researchers at The Center for Structural Genomics of Infectious 
147 Diseases (PDB 6WEN) (30) and the University of Wisconsin-Milwaukee (PDB 6WEY) (32).

148 Further analysis of the amino acid sequences used for expression and purification revealed that

149 our construct had 5 additional residues at the C-terminus (MKSEK) and differs slightly at the N-

150 terminus as well (GIE vs GE) relative to 6WEN. In addition, the sequence used to obtain the

151 structure of 6WEY is slightly shorter than SARS-CoV-2 Mac1 at both the N and C-terminal

152 regions (Fig. S2A). To assess the effect of these additional residues on crystallization, chain B

153 of the SARS-CoV-2 Mac1, which was traced to residue K172, was superimposed onto subunit A

154 of PDB 6W02 (31), a previously determined structure of ADP-ribose bound SARS-CoV-2 Mac1.

155 Analysis of the crystal packing of 6W02 indicates that the additional residues at the C-terminus

156 would clash with symmetry related molecules (Fig. S2B). This suggests that the presence of

157 these extra residues at the C-terminus likely prevented the generation of the more tightly packed

158 crystal forms obtained for 6W02 and 6WEY, which diffracted to high resolution.

The ADP-ribose binding pocket contained large regions of positive electron density

160 consistent with the docking of ADP-ribose (Fig. 3A). The adenine forms two hydrogen bonds

161 with D22-I23, which makes up a small loop between $\beta 2$ and the N-terminal half of $\alpha 1$. The side

162 chain of D22 interacts with N6, while the backbone nitrogen atom of I23 interacts with N1, in a

163 very similar fashion to the SARS-CoV macrodomain (6). This aspartic acid is known to be

164 critical for ADP-ribose binding for alphavirus macrodomains $(26,27)$. A large number of

165 contacts are made in the highly conserved loop between $\beta 3$ and $\alpha 2$ which includes many highly-

166 conserved residues, including a GGG (motif) and N40, which is completely conserved in all

167 enzymatically active macrodomains (33). N40 is positioned to make hydrogen bonds with the 3'

$168 \mathrm{OH}$ groups of the distal ribose, as well as a conserved water molecule (Fig. 3B-C). K44 and G46

169 also make hydrogen bonds with the 2' $\mathrm{OH}$ of the distal ribose, G48 makes contact with the 1' 
$170 \mathrm{OH}$ and a water that resides near the catalytic site, while the backbone nitrogen atom of V49

171 hydrogen bonds with the $\alpha$-phosphate. The other major interactions with ADP-ribose occur in

172 another highly conserved region consisting of residues G130, I131, and F132 that are in the loop

173 between $\beta 6$ and $\alpha 5$ (Fig. 3B). The $\alpha$-phosphate accepts a hydrogen bond from the nitrogen atom

174 of I131, while the $\beta$-phosphate accepts hydrogen bonds from the backbone nitrogen atom of

$175 \mathrm{G} 130$ and F132. The phenyl ring of F132 may make van der Waals interactions with the distal

176 ribose to stabilize it, which may contribute to binding and hydrolysis (34). Loops $\beta 3-\alpha 2$ and $\beta 6$ -

$177 \alpha 5$ are connected by an isoleucine bridge that forms a narrow channel around the diphosphate

178 which helps position the terminal ribose for water-mediated catalysis (6). Of all these residues, is

179 not exactly clear which ones are important for ADP-ribose binding, hydrolysis, or both.

180 Additionally, a network of direct contacts of ADP-ribose to solvent along with water mediated

181 contacts to the protein are shown (Fig. 3C).

182 Comparison of SARS-CoV-2 Mac1 with other CoV macrodomain structures. We

183 next sought to compare the SARS-CoV-2 Mac1 to other deposited structures of this protein.

184 Superposition with Apo (6WEN) and ADP-ribose complexed protein (6W02) yielded RMSD of

$1850.48 \AA$ (168 residues) and $0.37 \AA$ (165 residues), respectively, indicating a high degree of

186 similarity (Fig. S3A-B). Comparison of the ADP-ribose binding site of SARS-CoV-2 Mac1 with

187 that of the apo structure $(6 \mathrm{WEN})$ revealed minor conformational differences in order to

188 accommodate ADP-ribose binding. The loop between $\beta 3$ and $\alpha 2$ (H45-V49) undergoes a change

189 in conformation and the sidechain of F132 is moved out of the ADP-ribose binding site (Fig.

190 S3C). Our ADP-ribose bound structure is nearly identical to 6W02, except for slight deviations

191 in the $\beta 3-\alpha 2$ loop and an altered conformation of F156, where the aryl ring of F156 is moved

192 closer to the adenine ring (Fig. S3 C-D). However, this is likely a result of crystal packing as 
193 F156 adopts this conformation in each subunit and would likely clash with subunit residues

194 related by either crystallographic or non-crystallographic symmetry.

195 We next compared the ADP-ribose bound SARS-CoV-2 Mac1 structure with that of

196 SARS-CoV (PDB 2FAV) (6) and MERS-CoV (PDB 5HOL) (35) Mac1 proteins. Superposition

197 yielded RMSD deviations of $0.71 \AA$ (166 residues) and $1.06 \AA$ (161 residues) for $2 \mathrm{FAV}$ and

198 5HOL, respectively. Additionally, the ADP-ribose binding mode in the SARS-CoV and SARS-

199 CoV-2 structures almost perfectly superimposed (Fig. 4A-D). The conserved aspartic acid

200 residue (D22, SARS-CoV-2) that binds to adenine, is localized in a similar region in all 3

201 proteins although there are slight differences in the rotamers about the $\mathrm{C} \beta-\mathrm{C} \gamma$ bond. The angles

202 between the mean planes defined by the OD1, CG and OD2 atoms relative to SARS-CoV-2

$203 \mathrm{Mac} 1$ is $23.1^{\circ}$ and $46.5^{\circ}$ for the SARS-CoV and MERS-CoV Mac1 structures, respectively.

204 Another notable difference is that SARS-CoV and SARS-CoV-2 macrodomains have an

205 isoleucine (I23) following this aspartic acid while MERS-CoV has an alanine (A22). Conversely,

206 SARS-CoV-2 and SARS-CoV Mac1 have a valine instead of an isoleucine immediately

207 following the GGG motif (V49/I48). From these structures it appears that having two isoleucines

208 in this location would clash, and that lineage $\mathrm{B}$ and lineage $\mathrm{C} \beta$-CoVs has evolved in unique

209 ways to create space in this pocket (Fig. 4D and data not shown). Despite these small differences

210 in local structure, the overall structure of $\mathrm{CoV}$ Mac1 domains remain remarkably conserved, and

211 indicates they likely have similar biochemical activities and biological functions.

212 SARS-CoV, SARS-CoV-2, and MERS-CoV bind to ADP-ribose with similar

213 affinities. To determine if the CoV macrodomains had any noticeable differences in their ability

214 to bind ADP-ribose, we performed isothermal titration calorimetry (ITC), which measures the

215 energy released or absorbed during a binding reaction. Macrodomain proteins from human 
216 (Mdo2), SARS-CoV, MERS-CoV, and SARS-CoV-2 were purified (Fig. S1A) and tested for

217 their affinity to ADP-ribose. All CoV Mac1 proteins bound to ADP-ribose with low micromolar

218 affinity $(7-16 \mu \mathrm{M})$, while human Mdo2 bound with an affinity about 10-times stronger $(\sim 220$

$219 \mathrm{nM})$ (Fig. 5A-B). As a control we tested the ability of the MERS-CoV macrodomain to bind to

220 ATP, and only observed minimal binding with $\mathrm{mM}$ affinity (data not shown). At higher

221 concentrations, the SARS-CoV-2 macrodomain caused a slightly endothermic reaction,

222 potentially the result of protein aggregation or a change in conformation (Fig. 5A). The MERS-

223 CoV Mac1 had a greater affinity for ADP-ribose than SARS-CoV or SARS-CoV-2 Mac1 in the

224 ITC assay (Fig. 5A-B), however, our results found the differences between these macrodomain

225 proteins to be much closer than previously reported (9). As an alternate method to confirm ADP-

226 ribose binding, we conducted a thermal shift assay. All 4 macrodomains tested denatured at

227 higher temperatures with the addition of ADP-ribose (Fig. S4). We conclude that lineage B and

228 lineage $\mathrm{C} \beta$-CoV Mac1 proteins bind to ADP-ribose with similar affinities.

CoV macrodomains are MAR-hydrolases. To examine the MAR-hydrolase activity of

$230 \mathrm{CoV}$ Mac1, we first tested the viability of using ADP-ribose binding reagents to detect

231 MARylated protein. Previously, radiolabeled NAD ${ }^{+}$has been the primary method used to label

232 MARylated protein $(16,17)$. To create a MARylated substrate, the catalytic domain of the

233 PARP10 (GST-PARP10 CD) protein was incubated with $\mathrm{NAD}^{+}$, leading to its automodification.

234 PARP10 CD is a standard substrate that has been used extensively in the field to analyze the

235 activity of macrodomains $(16,18,26,27)$. PARP10 is highly upregulated upon CoV infection

$236(23,36)$ and is known to primarily auto-MARylate itself on acidic residues, which are the targets

237 of the MacroD2 class of macrodomains (27). We then tested a panel of anti-MAR, anti-PAR, or

238 both anti-MAR and anti-PAR binding reagents/antibodies for the ability to detect MARylated 
PARP10 by immunoblot. The anti-MAR and anti-MAR/PAR binding reagents, but not anti-PAR antibody, bound to MARylated PARP10 (Fig. S5). Therefore, in this work we utilized the anti-

241 MAR binding reagent to detect MARylated PARP10.

244 equimolar amounts of protein at $37^{\circ} \mathrm{C}$ and the reaction was stopped at 5, 10, 20, 30, 45 or 60

245 minutes (Fig. 6A). As a control, MARylated PARP10 was incubated alone at $37^{\circ} \mathrm{C}$ and collected

246 at similar time points (Fig. 6A and Fig. S6). Each reaction had equivalent amounts of

247 MARylated PARP10 and Mac1 which was confirmed by Coomassie Blue staining (Fig. 6A). An

248 immediate reduction of more than $50 \%$ band intensity was observed within five minutes, and the

249 ADP-ribose modification was nearly completely removed by SARS-CoV-2 Mac1 within 30

250 minutes (Fig. 6A). The MARylated PAPR10 bands intensities were calculated, plotted, and were

251 fit using non-linear regression (Fig. 6B). This result indicates that the SARS-CoV-2 Mac1

252 protein is a mono-ADP-ribosylhydrolase enzyme.

Next, we compared the MAR-hydrolase activity of Mac1 proteins from SARS-CoV-2,

254 SARS-CoV, and MERS-CoV and human (i.e., Mdo2). Specifically, we monitored the time-

255 dependent loss of substrate using immunoblotting (Fig. 6C) under equimolar (i.e., $1 \mu \mathrm{M}$

$256[\mathrm{Mac} 1]: 1 \mu \mathrm{M}$ [substrate]) and multiple-turnover conditions (i.e., $0.5 \mu \mathrm{M}$ [substrate]:0.1 $\mu \mathrm{M}$

$257[\mathrm{Mac1}]$ and $1.0 \mu \mathrm{M}$ [substrate]:0.1 $\mu \mathrm{M}$ [Mac1] ), with total protein amounts confirmed by

258 Coomassie blue staining (Fig. S7). The resulting substrate decay plots (Fig. 6D) were fit using

259 non-linear regression to determine the initial rate $(k)$ of substrate decay. Our results indicate that

260 the three CoV Mac1 proteins give rise to similar, but not identical, values of $k$ (Fig. 6D). The

261 SARS-CoV-2 Mac1 protein has a greater $k$ than the SARS-CoV or MERS-CoV Mac1 proteins, 
especially under multiple-turnover conditions, and all 3 viral macrodomains gave rise to a more rapid loss of substrate than the human Mdo2 enzyme (Fig. 6F). However, further enzymatic analyses of these proteins are warranted to more thoroughly understand their kinetics and

265 binding affinities associated with various MARylated substrates.

267 could remove PAR from proteins, we incubated these proteins with an auto-PARylated PARP1

268 protein. PARP1 was incubated with increasing concentrations of $\mathrm{NAD}^{+}$to create a range of

269 modification levels (Fig. S8). We incubated both partially and heavily modified PARP1 with all

270 four macrodomains and PARG as a positive control for 1 hour. While PARG completely

271 removed PAR, none of the macrodomain proteins removed PAR chains from PARP1 (Fig. 7).

272 We conclude that macrodomain proteins are unable to remove PAR from an automodified

273 PARP1 protein under these conditions.

macrodomains. Gel based assays as described above suffer from significant limitations in the

276 number of samples that can be done at once. A higher throughput assay will be needed to more

277 thoroughly investigate the activity of these enzymes and to screen for inhibitor compounds.

278 Based on the success of our antibody-based detection of MAR, we developed an ELISA assay

279 that has a similar ability to detect de-MARylation as our gel-based assay, but with the ability to

280 do so in a higher throughput manner (Fig. 8A). First, MARylated PARP10 was added to ELISA

281 plates. Next, the wells were washed and then incubated with different concentrations of the

282 SARS-CoV-2 Mac1 protein for $60 \mathrm{~min}$. After incubation, the wells were washed and treated with

283 anti-MAR binding reagent, followed by HRP-conjugated secondary antibody and the detection

284 reagent. As controls, we detected MARylated and non-MARylated PARP10 proteins bound to 
285 glutathione plates with anti-GST antibody and anti-MAR binding reagents and their

286 corresponding secondary antibodies (Fig. 8B). SARS-CoV-2 Mac1 was able to remove MAR

287 signal in a dose-dependent manner and plotted to a linear non-regression fitted line (Fig. 8C).

288 Based on these results, we believe that this ELISA assay will be a useful tool for screening

289 potential inhibitors of macrodomain proteins. 


\section{DISCUSSION}

Here we report the crystal structure of SARS-CoV-2 Mac1 and its enzyme activity in

292 vitro. Structurally, it has a conserved three-layered $\alpha / \beta / \alpha$ fold typical of the MacroD family of

293 macrodomains, and is extremely similar to other CoV Mac1 proteins (Fig. 2-4). The conserved

294 CoV macrodomain (Mac1) was initially described as an ADP-ribose-1"-phosphatase (ADRP), as

295 it was shown to be structurally similar to yeast enzymes that have this enzymatic activity (37).

296 Early biochemical studies confirmed this activity for CoV Mac1, though its phosphatase activity

297 for ADP-ribose-1"-phosphate was rather modest (6-8). Later, it was shown that mammalian

298 macrodomain proteins could remove ADP-ribose from protein substrates, indicating protein de-

299 ADP-ribosylation as a more likely function for the viral macrodomains $(33,38,39)$. Shortly

300 thereafter, the SARS-CoV, hCoV-229E, FIPV, several alphavirus, and the hepatitis E virus

301 macrodomains were demonstrated to have de-ADP-ribosylating activity (16-18). However, this

302 activity has not yet been reported for the MERS-CoV or SARS-CoV-2 Mac1 protein.

303 In this study, we show that the Mac1 proteins from SARS-CoV, MERS-CoV and SARS-

304 CoV-2 hydrolyze MAR from a protein substrate (Fig. 6). Their enzymatic activities were similar

305 despite sequence divergence of almost $60 \%$ between SARS-CoV-2 and MERS-CoV. However,

306 the initial rate associated with the loss of substrate was largest for the SARS-CoV-2 Mac1

307 protein, particularly under multiple-turnover conditions. It is unclear what structural or sequence

308 differences may account for the increased activity of the SARS-CoV-2 Mac1 protein under these

309 conditions, especially considering the pronounced structurally similarities between these

310 proteins, specifically the SARS-CoV Mac1 (0.71 $\AA$ RMSD). It is also unclear if these differences

311 would matter in the context of the virus infection, as the relative concentrations of Mac1 and its

312 substrate during infection is not known. We also compared these activities to the human Mdo2 
313 macrodomain. Mdo2 had a greater affinity for ADP-ribose than the viral enzymes, but had

314 significantly reduced enzyme activity in our experiments. Due to its high affinity for ADP-

315 ribose, it is possible that the Mdo2 protein was partially inhibited by rebinding to the MAR

316 product in these assays. Regardless, these results suggest that the human and viral proteins likely

317 have structural differences that alter their biochemical activities in vitro, indicating that it may be

318 possible to create viral macrodomain inhibitors that don't impact the human macrodomains. We

319 also compared the ability of these macrodomain proteins to hydrolyze PAR. None of the

320 macrodomains were able to hydrolyze either partially or heavily modified PARP1, further

321 demonstrating that the primary enzymatic activity of these proteins is to hydrolyze MAR (Fig.

$3227)$.

When analyzing viral macrodomain sequences, it is clear that they have at least 3 highly

324 conserved regions (Fig. 1B)(24). The first region includes the NAAN (37-40) and GGG (residues

325 46-48) motifs in the loop between $\beta 3$ and $\alpha 2$. The second domain includes a GIF (residues 130-

326 132) motif in the loop between $\beta 6$ and $\alpha 5$. The final conserved region is a VGP (residues 96-98)

327 motif at the end of $\beta 5$ and extends into the loop between $\beta 5$ and $\alpha 4$. Both of the first two

328 domains have well defined interactions with ADP-ribose (Fig. 3). However, no one has

329 addressed the role of the VGP residues, though our structure indicates that the glycine may

330 interact with a water molecule that makes contact with the $\beta$-phosphate. Identifying residues that

331 directly contribute to ADP-ribose binding, hydrolysis, or both by CoV Mac1 proteins will be

332 critical to determining the specific roles of ADP-ribose binding and hydrolysis in $\mathrm{CoV}$

333 replication and pathogenesis.

334 While all previous studies of macrodomain de-ADP-ribosylation have primarily used

335 radiolabeled substrate, we obtained highly repeatable and robust data utilizing ADP-ribose 
336 binding reagents designed to specifically recognize MAR $(40,41)$. The use of these binding

337 reagents should enhance the feasibility of this assay for many labs that are not equipped for

338 radioactive work. Utilizing these binding reagents, we further developed an ELISA assay for de-

339 MARylation that has the ability to dramatically increase the number of samples that can be

340 analyzed compared to the gel-based assay. To our knowledge, previously developed ELISA

341 assays were used to measure ADP-ribosyltransferase activities (42) but no ELISA has been

342 established to test the ADP-ribosylhydrolase activity of macrodomain proteins. This ELISA

343 assay should be useful to those in the field to screen compounds for macrodomain inhibitors that

344 could be either valuable research tools or potential therapeutics.

345 The functional importance of the $\mathrm{CoV}$ Mac1 domain has been demonstrated in several

346 reports, mostly utilizing the mutation of a highly conserved asparagine that mediates contact with

347 the distal ribose (Fig. 3B) $(18,21,22)$. However, the physiological relevance of Mac1 during

348 SARS-CoV-2 infection has yet to be determined. In addition, the proteins that are targeted by the

349 CoV Mac1 for de-ADP-ribosylation remains unknown. Unfortunately, there are no known

350 compounds that inhibit this domain that could help identify the functions of this protein during

351 infection. The outbreak of COVID-19 has illustrated an urgent need for developing multiple

352 therapeutic drugs targeting conserved coronavirus proteins. Mac1 appears to be an ideal

353 candidate for further drug development based on: $i$ ) its highly conserved structure and

354 biochemical activities within CoVs; and ii) its importance for multiple CoVs to cause disease.

355 Targeting Mac1 may also have the benefit of enhancing the innate immune response, as we have

356 shown that Mac1 is required for some CoVs to block IFN production $(18,23)$. Considering that

357 Mac1 proteins from divergent $\alpha \mathrm{CoV}$ s such as 229E and FIPV also have de-ADP-ribosylating

358 activity $(16,17)$, it is possible that compounds targeting Mac1 could prevent disease caused by 
359 of wide variety of $\mathrm{CoV}$, including those of veterinary importance like porcine epidemic diarrhea

360 virus (PEDV). Additionally, compounds that inhibit Mac1 in combination with the structure

361 could help identify the mechanisms it uses to bind to its biologically relevant protein substrates,

362 remove ADP-ribose from these proteins, and potentially define the precise function for Mac1 in

363 SARS-CoV-2 replication and pathogenesis. In conclusion, the results described here will be

364 critical for the design and development of highly-specific Mac1 inhibitors that could be used

365 therapeutically to mitigate COVID-19 or future CoV outbreaks. 


\section{METHODS}

368 Plasmids

The SARS-CoV macrodomain (Mac1) (residues 1000-1172 of pp1a) was cloned into the

370 pET21a+ expression vector with an N-terminal His tag. The MERS-CoV Mac1 (residues 1110-

3711273 of pp1a) was also cloned into pET21a+ with a C-terminal His tag. SARS-CoV-2 Mac1

372 (residues 1023-1197 of pp1a) was cloned into the pET30a+ expression vector with an N-terminal

373 His tag and a TEV cleavage site (Synbio). The pETM-CN Mdo2 Mac1 (residues 7-243)

374 expression vector with an N-terminal His-TEV-V5 tag and the pGEX4T-PARP10-CD (residues

375 818-1025) expression vector with an N-terminal GST tag were previously described (33). All

376 plasmids were confirmed by restriction digest, PCR, and direct sequencing.

\section{Protein Expression and Purification}

A single colony of $E$. coli cells (C41(DE3)) containing plasmids harboring the constructs

379 of the macrodomain proteins was inoculated into $10 \mathrm{~mL} \mathrm{LB}$ media and grown overnight at $37^{\circ} \mathrm{C}$

380 with shaking at $250 \mathrm{rpm}$. The overnight culture was transferred to a shaker flask containing $2 \mathrm{X}$

381 1L TB media at $37^{\circ} \mathrm{C}$ until the OD600 reached 0.7 . The proteins were either induced with 0.4

$382 \mathrm{mM}$ IPTG at $37^{\circ} \mathrm{C}$ for 3 hours, or $17^{\circ} \mathrm{C}$ for 20 hours. Cells were pelleted at $3500 \times \mathrm{g}$ for $10 \mathrm{~min}$

383 and frozen at $-80^{\circ} \mathrm{C}$. Frozen cells were thawed at room temperature, resuspended in $50 \mathrm{mM}$ Tris

384 (pH 7.6), $150 \mathrm{mM} \mathrm{NaCl}$, and sonicated using the following cycle parameters: Amplitude: 50\%,

385 Pulse length: 30 seconds, Number of pulses: 12, while incubating on ice for $>1$ min between

386 pulses. The soluble fraction was obtained by centrifuging the cell lysate at 45,450 $\times \mathrm{g}$ for 30

387 minutes at $4^{\circ} \mathrm{C}$. The expressed soluble proteins were purified by affinity chromatography using

388 a $5 \mathrm{ml}$ prepacked HisTrap HP column on an AKTA Pure protein purification system (GE

389 Healthcare). The fractions were further purified by size-exclusion chromatography (SEC) with a 
Superdex 75 10/300 GL column equilibrated with 20mM Tris (pH 8.0), $150 \mathrm{mM} \mathrm{NaCl}$ and the

391 protein sized as a monomer relative to the column calibration standards. To cleave off the His tag

392 from the SARS-CoV-2 Mac1, purified TEV protease was added to purified SARS-CoV-2 Mac1

393 protein at a ratio of 1:10 (w/w), and then passed back through the Ni-NTA HP column. Protein

394 was collected in the flow through and equilibrated with $20 \mathrm{mM}$ Tris (pH 8.0), $150 \mathrm{mM} \mathrm{NaCl}$.

395 The SARS-CoV-2 Mac1, free from the N-terminal 6X-His tag, was used for subsequent

396 crystallization experiments.

For the PARP10-CD protein, the cell pellet was resuspended in $50 \mathrm{mM}$ Tris- $\mathrm{HCl}(\mathrm{pH}$

400 equilibrated with the same buffer for 2 hours, then applied to a gravity flow column to allow

401 unbound proteins to flow through. The column was washed with the resuspension buffer till the

402 absorbance at $280 \mathrm{~nm}$ reached baseline. The bound protein was eluted out of the column with

403 resuspension buffer containing $20 \mathrm{mM}$ reduced glutathione and then dialyzed back into the

404 resuspension buffer overnight at $4^{\circ} \mathrm{C}$.

\section{Isothermal Titration Calorimetry}

All ITC titrations were performed on a MicroCal PEAQ-ITC instrument (Malvern

407 Pananalytical Inc., MA). All reactions were performed in $20 \mathrm{mM}$ Tris $\mathrm{pH}$ 7.5, $150 \mathrm{mM} \mathrm{NaCl}$

408 using $100 \mu \mathrm{M}$ of all macrodomain proteins at $25^{\circ} \mathrm{C}$. Titration of $2 \mathrm{mM}$ ADP-ribose or ATP

409 (MilliporeSigma) contained in the stirring syringe included a single $0.4 \mu \mathrm{L}$ injection, followed by

41018 consecutive injections of $2 \mu \mathrm{L}$. Data analysis of thermograms was analyzed using one set of

411 binding sites model of the MicroCal ITC software to obtain all fitting model parameters for the

412 experiments. 


\section{Differential Scanning Fluorimetry (DSF)}

415 Diagnostics). In total, a $15 \mu \mathrm{L}$ mixture containing $8 X$ SYPRO Orange (Invitrogen), and $10 \mu \mathrm{M}$

416 macrodomain protein in buffer containing $20 \mathrm{mM}$ Hepes, $\mathrm{NaOH}, \mathrm{pH} 7.5$ and various

417 concentrations of ADP-ribose were mixed on ice in 384-well PCR plate (Roche). Fluorescent

418 signals were measured from 25 to $95^{\circ} \mathrm{C}$ in $0.2{ }^{\circ} \mathrm{C} / 30$-s steps (excitation, $470-505 \mathrm{~nm}$; detection,

$419540-700 \mathrm{~nm})$. The main measurements were carried out in triplicate. Data evaluation and Tm

420 determination involved use of the Roche LightCycler ${ }^{\circledR} 480$ Protein Melting Analysis software,

421 and data fitting calculations involved the use of single site binding curve analysis on Graphpad

422 Prism.

423 MAR Hydrolase Assays

424 Automodification of PARP10-CD protein: A $10 \mu \mathrm{M}$ solution of purified PAPR10-CD

425 protein was incubated for 20 minutes at $37^{\circ} \mathrm{C}$ with $1 \mathrm{mM}$ final concentration of $\beta$-Nicotinamide

426 Adenine Dinucleotide $\left(\beta \mathrm{NAD}^{+}\right)$(Millipore-Sigma) in a reaction buffer (50 mM HEPES, 150

$427 \mathrm{mM} \mathrm{NaCl}, 0.2 \mathrm{mM}$ DTT, and 0.02\% NP-40). MARylated PARP10 was aliquoted and stored at $42880^{\circ} \mathrm{C}$.

429 PAPR10-CD ADP-ribose hydrolysis: All reactions were performed at $37^{\circ} \mathrm{C}$ for the

430 designated time. A $1 \mu \mathrm{M}$ solution of MARylated PARP10-CD and purified Mac1 protein was

431 added in the reaction buffer (50 mM HEPES, $150 \mathrm{mM} \mathrm{NaCl}, 0.2 \mathrm{mM}$ DTT, and 0.02\% NP-40).

432 The reaction was stopped with addition of 2 X Laemmli sample buffer containing $10 \% \beta$ 433 mercaptoethanol.

434 Protein samples were heated at $95^{\circ} \mathrm{C}$ for 5 minutes before loading and separated onto

435 SDS-PAGE cassette (Thermo Fisher Scientific Bolt ${ }^{\mathrm{TM}}$ 4-12\% Bis-Tris Plus Gels) in MES 
running buffer. For direct protein detection, the SDS-PAGE gel was stained using InstantBlue ${ }^{\circledR}$

437 Protein Stain (Expedeon). For immunoblotting, the separated proteins were transferred onto

438 polyvinylidene difluoride (PVDF) membrane using iBlot ${ }^{\mathrm{TM}} 2$ Dry Blotting System

439 (ThermoFisher Scientific). The blot was blocked with 5\% skim milk in PBS containing $0.05 \%$

440 Tween-20 and probed with anti-mono or poly ADP-ribose binding reagents/antibodies

441 MABE1076 ( $\alpha$-MAR), MABC547 ( $\alpha$-PAR), MABE1075 ( $\alpha$-MAR/PAR) (Millipore-Sigma) and

442 anti-GST tag monoclonal antibody MA4-004 (ThermoFisher Scientific). The primary antibodies

443 were detected with secondary infrared anti-rabbit and anti-mouse antibodies (LI-COR

444 Biosciences). All immunoblots were visualized using Odyssey ${ }^{\circledR}$ CLx Imaging System (LI-COR

445 Biosciences). The images were quantitated using Image J (National Institutes for Health (NIH))

446 or Image Studio software.

448 decay associated with the four macrodomains, each data set represented in the substrate decay

449 immunoblots in Fig. 6C, were fitted to a decaying exponential with the following functional

450 form: ([S $\left.]_{\text {initial }}[\mathrm{S}]_{\text {final }}\right) e^{\left.\left(-[k / \mathrm{S}]_{\text {initial }}\right) t\right]}+[\mathrm{S}]_{\text {final }}$ (Mathematica 12, Wolfram Alpha). The decay plots

451 and resulting values for the fitted parameter $k$ along with statistic uncertainty (SD) are shown in

452 Fig. 6D.

ELISA-based MAR hydrolysis: ELISA Well-Coated ${ }^{\mathrm{TM}}$ Glutathione plates (G-Biosciences,

454 USA) were washed with phosphate-buffered saline (PBS) containing $0.05 \%$ Tween-20 (PBS-T)

455 and incubated with $50 \mu \mathrm{L}$ of $100 \mathrm{nM}$ automodified MARylated PARP10-CD in PBS for one

456 hour under room temperature. Following four washes with PBS-T, variable concentrations of

457 SARS-CoV-2 Mac1 were incubated with MARylated PARP10-CD for 60 minutes at $37^{\circ} \mathrm{C}$.

458 Purified macrodomains were 2-fold serially diluted starting at $100 \mathrm{nM}$ in reaction buffer prior to 
addition to MARylated PARP10-CD. Subsequently, ELISA wells were washed four times with (Millipore-Sigma MAB1076) diluted 1:5,000 in $5 \mathrm{mg} / \mathrm{ml} \mathrm{BSA} \mathrm{in} \mathrm{PBS-T} \mathrm{(BSA5-PBS-T)} \mathrm{for} 1$

462 hour at room temperature. After four additional washes with PBS-T, each well was incubated 463 with $50 \mu \mathrm{L}$ diluted 1:5,000 in BSA5-PBS-T of anti-rabbit-HRP (SouthernBiotech, USA) or anti-

464 mouse-HRP (Rockland Immunochemicals, USA) conjugate for 1 hour at room temperature. The 465 plate was washed four times with PBS-T and $100 \mu \mathrm{L}$ of TMB peroxidase substrate solution

466 (SouthernBiotech, USA) was added to each well and incubated for 10 minutes. The peroxidase 467 reaction was stopped with $50 \mu \mathrm{L}$ per well of $1 \mathrm{M} \mathrm{HCl}$ before proceeding to reading. Absorbance 468 was measured at $450 \mathrm{~nm}$ and subtracted from $620 \mathrm{~nm}$ using Biotek Powerwave XS plate reader 469 (BioTek). As controls, MARylated PARP10-CD and non-MARylated PARP10 were detected 470 with both anti-MAR and anti-GST antibodies. The absorbance of non-MARylated PARP10-CD

471 detected with anti-MAR antibody was used to establish the background signal. The \% signal 472 remaining was calculated by dividing the experimental signal (+ enzyme) minus background by 473 the control (no enzyme) minus the background.

\section{PAR Hydrolase Assay}

Automodification of PARP1 protein: PARP1 was incubated with increasing

476 concentrations of $\mathrm{NAD}^{+}$to generate a range of PARP1 automodification levels. Highly purified

477 human 6X-His-PARP1 (43) (5 $\mu \mathrm{g})$ was incubated for $30 \mathrm{~min}$ at $30^{\circ} \mathrm{C}$ in a reaction buffer

478 containing $100 \mathrm{mM}$ Tris- $\mathrm{HCl} \mathrm{pH} 8.0,10 \mathrm{mM} \mathrm{MgCl} 2,10 \%$ (v/v) glycerol, $10 \mathrm{mM}$ DTT, 0 to 500

$479 \mu \mathrm{M} \mathrm{NAD}+, 10 \%(\mathrm{v} / \mathrm{v})$ ethanol and $25 \mu \mathrm{g} / \mathrm{mL}$ calf thymus activated DNA (Sigma-Aldrich). 
automodified with $500 \mu \mathrm{M} \mathrm{NAD}^{+}$were used as substrates for the de-PARylation assays.

483 Recombinant macrodomain protein $(1 \mu \mathrm{g})$ was supplemented to the reaction buffer $(100 \mathrm{mM}$

484 Tris- $\mathrm{HCl} \mathrm{pH}$ 8.0, 10\% (v/v) glycerol and $10 \mathrm{mM} \mathrm{DTT})$ containing automodified PARP1 and

485 incubated for 1 hour at $37^{\circ} \mathrm{C}$. Recombinant PARG $(1 \mu \mathrm{g})$ was used as a positive control for PAR

486 erasing (44). Reaction mixtures were resolved on $4-12 \%$ Criterion ${ }^{\mathrm{TM}}$ XT Bis-Tris protein gels,

487 transferred onto nitrocellulose membrane and probed with the anti-PAR polyclonal antibody 96-

48810.

489 Structure Determination

$491 \mathrm{mM}$ Tris $\mathrm{pH} 8.0$ was concentrated to $13.8 \mathrm{mg} / \mathrm{mL}$ for crystallization screening. All crystallization

492 experiments were setup using an NT8 drop-setting robot (Formulatrix Inc.) and UVXPO MRC

493 (Molecular Dimensions) sitting drop vapor diffusion plates at $18^{\circ} \mathrm{C} .100 \mathrm{~nL}$ of protein and 100

$494 \mathrm{~nL}$ crystallization solution were dispensed and equilibrated against $50 \mu \mathrm{L}$ of the latter. The

495 SARS-CoV-2 Mac1 complex with ADP-ribose was prepared by adding the ligand, from a 100

$496 \mathrm{mM}$ stock in water, to the protein at a final concentration of $2 \mathrm{mM}$. Crystals that were obtained in

497 1-2 days from the Salt Rx HT screen (Hampton Research) condition E10 (1.8 M

$498 \mathrm{NaH}_{2} \mathrm{PO}_{4} / \mathrm{K}_{2} \mathrm{HPO}_{4}, \mathrm{pH}$ 8.2). Refinement screening was conducted using the additive screen HT

499 (Hampton Research) by supplementing 10\% of each additive to the Salt Rx HT E10 condition in

500 a new 96-well UVXPO crystallization plate. The crystals used for data collection were obtained

501 from Salt Rx HT E10 supplemented with 0.1 M NDSB-256 from the additive screen (Fig. S1).

502 Samples were transferred to a fresh drop composed of $80 \%$ crystallization solution and $20 \%$

503 (v/v) PEG 200 and stored in liquid nitrogen. X-ray diffraction data were collected at the 
Advanced Photon Source, IMCA-CAT beamline 17-ID using a Dectris Eiger 2X 9M pixel array

505 detector.

Structure Solution and Refinement: Intensities were integrated using XDS $(45,46)$ via

507 Autoproc (47) and the Laue class analysis and data scaling were performed with Aimless (48).

508 Notably, a pseudo-translational symmetry peak was observed at $(0,0.310 .5)$ that was $44.6 \%$ of

509 the origin. Structure solution was conducted by molecular replacement with Phaser (49) using a

510 previously determined structure of ADP-ribose bound SARS-CoV-2 Mac1 (PDB 6W02) as the

511 search model. The top solution was obtained in the space group $P 2_{1}$ with four molecules in the

512 asymmetric unit. Structure refinement and manual model building were conducted with Phenix

513 (50) and Coot (51) respectively. Disordered side chains were truncated to the point for which

514 electron density could be observed. Structure validation was conducted with Molprobity (52) and

515 figures were prepared using the CCP4MG package (53). Superposition of the macrodomain

516 structures was conducted with GESAMT (54).

\section{Statistical Analysis}

All statistical analyses were done using an unpaired two-tailed student's t-test to assess

519 differences in mean values between groups, and graphs are expressed as mean \pm SD. Significant $p$

520 values are denoted with $* \mathrm{p} \leq 0.05$

\section{ACCESSION CODES}

The coordinates and structure factors for SARS-CoV-2 Mac1 were deposited to the

523 Worldwide Protein Databank (wwPDB) with the accession code 6WOJ.

\section{ACKNOWLEDGEMENTS}

We'd like to thank Ivan Ahel and Gytis Jankevicius (Oxford University) for providing

526 protein expression plasmids; John Pascal (University of Montreal) and Marie-France Langelier 
527 (Universite de Montreal) for providing PARP1; and Wenqing Xu (University of Washington) for

528 providing PARG. This research was funded by the National Institutes of Health (NIH) grant

529 numbers P20 GM113117, P30GM110761, and AI134993-01, and University of Kansas start-up

530 funds to A.R.F, and the Canadian Institutes of Health Research grant number MOP-418863 to

531 G.G.P. Use of the IMCA-CAT beamline 17-ID at the Advanced Photon Source was supported by

532 the companies of the Industrial Macromolecular Crystallography Association through a contract

533 with Hauptman-Woodward Medical Research Institute. Use of the Advanced Photon Source was

534 supported by the U.S. Department of Energy, Office of Science, Office of Basic Energy

535 Sciences, under Contract No. DE-AC02-06CH11357. 


\section{AUTHOR CONTRIBUTIONS}

538 Conceptualization: ARF, YMOA, GGP

539 Data curation: YMOA, SL, JPG, ARF, EDH

540 Formal analysis: YMOA, DKJ, AR, SL, ARF, EDH

541 Funding acquisition: GGP, SL, ARF

542 Investigation: YMOA, MMK, AR, JPG, LN, PM, KPB

543 Methodology: YMOA, GGP, AR, JPG, EDH, SL, ARF

544 Project administration: GGP, SL, ARF

545 Resources: AR, SL, PG, ARF

546 Supervision: AR, GGP, SL ARF

547 Validation: YMOA, SL, AR, JPG, GGP, ARF

548 Visualization: YMOA, ARF, AR, SL, JPG

549 Writing - original draft: YMOA, SL, ARF

550 Writing - review \& editing: all authors 


\section{REFERENCES}

1. Zhou P, Yang XL, Wang XG, Hu B, Zhang L, Zhang W, Si HR, Zhu Y, Li B, Huang CL, Chen HD, Chen J, Luo Y, Guo H, Jiang RD, Liu MQ, Chen Y, Shen XR, Wang X, Zheng XS, Zhao K, Chen QJ, Deng F, Liu LL, Yan B, Zhan FX, Wang YY, Xiao GF, Shi ZL. 2020. A pneumonia outbreak associated with a new coronavirus of probable bat origin. Nature 579:270-273.

2. Coronaviridae Study Group of the International Committee on Taxonomy of V. 2020. The species Severe acute respiratory syndrome-related coronavirus: classifying 2019nCoV and naming it SARS-CoV-2. Nat Microbiol 5:536-544.

3. Srinivasan S, Cui H, Gao Z, Liu M, Lu S, Mkandawire W, Narykov O, Sun M, Korkin D. 2020. Structural Genomics of SARS-CoV-2 Indicates Evolutionary Conserved Functional Regions of Viral Proteins. Viruses 12:360.

4. Wu C, Liu Y, Yang Y, Zhang P, Zhong W, Wang Y, Wang Q, Xu Y, Li M, Li X, Zheng M, Chen L, Li H. 2020. Analysis of therapeutic targets for SARS-CoV-2 and discovery of potential drugs by computational methods. Acta Pharm Sin B doi:10.1016/j.apsb.2020.02.008.

5. Fehr AR, Perlman S. 2015. Coronaviruses: An Overview of Their Replication and Pathogenesis, p 1-23. In Maier HJ, Bickerton E, Britton P (ed), Coronaviruses, vol 1282. Springer New York.

6. Egloff MP, Malet H, Putics A, Heinonen M, Dutartre H, Frangeul A, Gruez A, Campanacci V, Cambillau C, Ziebuhr J, Ahola T, Canard B. 2006. Structural and functional basis for ADP-ribose and poly(ADP-ribose) binding by viral macro domains. $\mathrm{J}$ Virol 80:8493-502.

7. Putics A, Filipowicz W, Hall J, Gorbalenya AE, Ziebuhr J. 2005. ADP-ribose-1"monophosphatase: a conserved coronavirus enzyme that is dispensable for viral replication in tissue culture. J Virol 79:12721-31.

8. Saikatendu KS, Joseph JS, Subramanian V, Clayton T, Griffith M, Moy K, Velasquez J, Neuman BW, Buchmeier MJ, Stevens RC, Kuhn P. 2005. Structural basis of severe acute respiratory syndrome coronavirus ADP-ribose-1"-phosphate dephosphorylation by a conserved domain of nsP3. Structure 13:1665-75.

9. Cho CC, Lin MH, Chuang CY, Hsu CH. 2016. Macro Domain from Middle East Respiratory Syndrome Coronavirus (MERS-CoV) Is an Efficient ADP-ribose Binding Module: CRYSTAL STRUCTURE AND BIOCHEMICAL STUDIES. J Biol Chem 291:4894-902.

10. Xu Y, Cong L, Chen C, Wei L, Zhao Q, Xu X, Ma Y, Bartlam M, Rao Z. 2009. Crystal structures of two coronavirus ADP-ribose-1"-monophosphatases and their complexes with ADP-Ribose: a systematic structural analysis of the viral ADRP domain. J Virol 83:1083-92.

11. Tan J, Vonrhein C, Smart OS, Bricogne G, Bollati M, Kusov Y, Hansen G, Mesters JR, Schmidt CL, Hilgenfeld R. 2009. The SARS-unique domain (SUD) of SARS coronavirus contains two macrodomains that bind G-quadruplexes. PLoS Pathog 5:e1000428.

12. Chatterjee A, Johnson MA, Serrano P, Pedrini B, Joseph JS, Neuman BW, Saikatendu K, Buchmeier MJ, Kuhn P, Wuthrich K. 2009. Nuclear magnetic resonance structure shows that the severe acute respiratory syndrome coronavirus-unique domain contains a macrodomain fold. J Virol 83:1823-36. 
13. Makrynitsa GI, Ntonti D, Marousis KD, Birkou M, Matsoukas MT, Asami S, Bentrop D, Papageorgiou N, Canard B, Coutard B, Spyroulias GA. 2019. Conformational plasticity of the VEEV macro domain is important for binding of ADP-ribose. J Struct Biol 206:119-127.

14. Malet H, Coutard B, Jamal S, Dutartre H, Papageorgiou N, Neuvonen M, Ahola T, Forrester N, Gould EA, Lafitte D, Ferron F, Lescar J, Gorbalenya AE, de Lamballerie X, Canard B. 2009. The crystal structures of Chikungunya and Venezuelan equine encephalitis virus nsP3 macro domains define a conserved adenosine binding pocket. $\mathrm{J}$ Virol 83:6534-45.

15. Rack JG, Perina D, Ahel I. 2016. Macrodomains: Structure, Function, Evolution, and Catalytic Activities. Annu Rev Biochem 85:431-54.

16. Li C, Debing Y, Jankevicius G, Neyts J, Ahel I, Coutard B, Canard B. 2016. Viral Macro Domains Reverse Protein ADP-Ribosylation. J Virol 90:8478-86.

17. Eckei L, Krieg S, Butepage M, Lehmann A, Gross A, Lippok B, Grimm AR, Kummerer BM, Rossetti G, Luscher B, Verheugd P. 2017. The conserved macrodomains of the nonstructural proteins of Chikungunya virus and other pathogenic positive strand RNA viruses function as mono-ADP-ribosylhydrolases. Sci Rep 7:41746.

18. Fehr AR, Channappanavar R, Jankevicius G, Fett C, Zhao J, Athmer J, Meyerholz DK, Ahel I, Perlman S. 2016. The Conserved Coronavirus Macrodomain Promotes Virulence and Suppresses the Innate Immune Response during Severe Acute Respiratory Syndrome Coronavirus Infection. mBio 7:e01721-16.

19. Kim DS, Challa S, Jones A, Kraus WL. 2020. PARPs and ADP-ribosylation in RNA biology: from RNA expression and processing to protein translation and proteostasis. Genes Dev 34:302-320.

20. Fehr AR, Singh SA, Kerr CM, Mukai S, Higashi H, Aikawa M. 2020. The impact of PARPs and ADP-ribosylation on inflammation and host-pathogen interactions. Genes Dev 34:341-359.

21. Eriksson KK, Cervantes-Barragan L, Ludewig B, Thiel V. 2008. Mouse hepatitis virus liver pathology is dependent on ADP-ribose-1"-phosphatase, a viral function conserved in the alpha-like supergroup. J Virol 82:12325-34.

22. Fehr AR, Athmer J, Channappanavar R, Phillips JM, Meyerholz DK, Perlman S. 2015. The nsp3 macrodomain promotes virulence in mice with coronavirus-induced encephalitis. J Virol 89:1523-36.

23. Grunewald ME, Chen Y, Kuny C, Maejima T, Lease R, Ferraris D, Aikawa M, Sullivan CS, Perlman S, Fehr AR. 2019. The coronavirus macrodomain is required to prevent PARP-mediated inhibition of virus replication and enhancement of IFN expression. PLoS Pathog 15:e1007756.

24. Alhammad YMO, Fehr AR. 2020. The Viral Macrodomain Counters Host Antiviral ADP-Ribosylation. Viruses 12:384.

25. Abraham R, Hauer D, McPherson RL, Utt A, Kirby IT, Cohen MS, Merits A, Leung AKL, Griffin DE. 2018. ADP-ribosyl-binding and hydrolase activities of the alphavirus nsP3 macrodomain are critical for initiation of virus replication. Proc Natl Acad Sci U S A 115:E10457-E10466.

26. Abraham R, McPherson RL, Dasovich M, Badiee M, Leung AKL, Griffin DE. 2020. Both ADP-Ribosyl-Binding and Hydrolase Activities of the Alphavirus nsP3 Macrodomain Affect Neurovirulence in Mice. mBio 11. 
27. McPherson RL, Abraham R, Sreekumar E, Ong SE, Cheng SJ, Baxter VK, Kistemaker Chikungunya virus macrodomain is critical for virus replication and virulence. Proc Natl Acad Sci U S A 114:1666-1671.

28. Parvez MK. 2015. The hepatitis E virus ORF1 'X-domain' residues form a putative macrodomain protein/Appr-1"-pase catalytic-site, critical for viral RNA replication. Gene 566:47-53.

31. Michalska K, Kim, Y., Jedrzejczak, R., Maltseva, N., Endres, M., Mececar, A.,

29. Vuksanovic N, Silvaggi, N.R. National Science Foundation (NSF, United States). 2020. High-resolution structure of the SARS-CoV-2 NSP3 Macro X domain doi: 10.2210/pdb6WEY/pdb. doi:10.2210/pdb6WEY/pdb.

30. Michalska K, Stols, L., Jedrzejczak, R., Endres, M., Babnigg, G., Kim, Y., Joachimiak, A., Center for Structural Genomics of Infectious Diseases (CSGID). 2020. Crystal Structure of ADP ribose phosphatase of NSP3 from SARS-CoV-2 in the apo doi: 10.2210/pdb6WEN/pdb. doi:10.2210/pdb6wen/pdb. Joachimiak, A., Center for Structural Genomics of Infectious Diseases (CSGID). 2020. Crystal Structure of ADP ribose phosphatase of NSP3 from SARS CoV-2 in the complex with ADP ribose doi: 10.2210/pdb6W02/pdb. doi:10.2210/pdb6W02/pdb.

32. Frick DN, Virdi RS, Vuksanovic N, Dahal N, Silvaggi NR. 2020. Molecular Basis for ADP-Ribose Binding to the Mac1 Domain of SARS-CoV-2 nsp3. Biochemistry (Mosc) 59:2608-2615.

33. Jankevicius G, Hassler M, Golia B, Rybin V, Zacharias M, Timinszky G, Ladurner AG. 2013. A family of macrodomain proteins reverses cellular mono-ADP-ribosylation. Nat Struct Mol Biol 20:508-14.

34. Leung AKL, McPherson RL, Griffin DE. 2018. Macrodomain ADP-ribosylhydrolase and the pathogenesis of infectious diseases. PLoS Pathog 14:e1006864.

35. Lei J, Kusov Y, Hilgenfeld R. 2018. Nsp3 of coronaviruses: Structures and functions of a large multi-domain protein. Antiviral Res 149:58-74.

36. Heer CD, Sanderson DJ, Alhammad YMO, Schmidt MS, Trammell SAJ, Perlman S, Cohen MS, Fehr AR, Brenner C. 2020. Coronavirus and PARP expression dysregulate the NAD Metabolome: a potentially actionable component of innate immunity. bioRxiv doi:10.1101/2020.04.17.047480.

37. Shull NP, Spinelli SL, Phizicky EM. 2005. A highly specific phosphatase that acts on ADP-ribose 1"-phosphate, a metabolite of tRNA splicing in Saccharomyces cerevisiae. Nucleic Acids Res 33:650-60.

38. Rosenthal F, Feijs KL, Frugier E, Bonalli M, Forst AH, Imhof R, Winkler HC, Fischer D, Caflisch A, Hassa PO, Luscher B, Hottiger MO. 2013. Macrodomain-containing proteins are new mono-ADP-ribosylhydrolases. Nat Struct Mol Biol 20:502-7.

39. Sharifi R, Morra R, Appel CD, Tallis M, Chioza B, Jankevicius G, Simpson MA, Matic I, Ozkan E, Golia B, Schellenberg MJ, Weston R, Williams JG, Rossi MN, Galehdari H, Krahn J, Wan A, Trembath RC, Crosby AH, Ahel D, Hay R, Ladurner AG, Timinszky G, Williams RS, Ahel I. 2013. Deficiency of terminal ADP-ribose protein glycohydrolase TARG1/C6orf130 in neurodegenerative disease. EMBO J 32:1225-37. 
41. Affar EB, Duriez PJ, Shah RG, Winstall E, Germain M, Boucher C, Bourassa S, Kirkland poly(ADP-ribose) synthesized in vitro and in vivo. Biochim Biophys Acta 1428:137-46.

42. Asokanathan C, Tierney S, Ball CR, Buckle G, Day A, Tanley S, Bristow A, Markey K, Xing D, Yuen CT. 2018. An ELISA method to estimate the mono ADPribosyltransferase activities: e.g in pertussis toxin and vaccines. Anal Biochem 540541:15-19.

43. Langelier MF, Planck JL, Servent KM, Pascal JM. 2011. Purification of human PARP-1 and PARP-1 domains from Escherichia coli for structural and biochemical analysis. Methods Mol Biol 780:209-26.

44. Wang Z, Gagne JP, Poirier GG, Xu W. 2014. Crystallographic and biochemical analysis of the mouse poly(ADP-ribose) glycohydrolase. PLoS One 9:e86010.

45. Kabsch W. 1988. Evaluation of Single-Crystal X-Ray-Diffraction Data from a PositionSensitive Detector. J Appl Crystallogr 21:916-924.

46. Kabsch W. 2010. Xds. Acta Crystallogr D Biol Crystallogr 66:125-32.

47. Vonrhein C, Flensburg C, Keller P, Sharff A, Smart O, Paciorek W, Womack T, Bricogne G. 2011. Data processing and analysis with the autoPROC toolbox. Acta Crystallogr D Biol Crystallogr 67:293-302.

48. Evans PR. 2011. An introduction to data reduction: space-group determination, scaling and intensity statistics. Acta Crystallogr D Biol Crystallogr 67:282-92.

49. McCoy AJ, Grosse-Kunstleve RW, Adams PD, Winn MD, Storoni LC, Read RJ. 2007. Phaser crystallographic software. J Appl Crystallogr 40:658-674.

50. Adams PD, Afonine PV, Bunkoczi G, Chen VB, Davis IW, Echols N, Headd JJ, Hung LW, Kapral GJ, Grosse-Kunstleve RW, McCoy AJ, Moriarty NW, Oeffner R, Read RJ, Richardson DC, Richardson JS, Terwilliger TC, Zwart PH. 2010. PHENIX: a comprehensive Python-based system for macromolecular structure solution. Acta Crystallogr D Biol Crystallogr 66:213-21.

51. Emsley P, Lohkamp B, Scott WG, Cowtan K. 2010. Features and development of Coot. Acta Crystallogr D Biol Crystallogr 66:486-501.

52. Chen VB, Arendall WB, 3rd, Headd JJ, Keedy DA, Immormino RM, Kapral GJ, Murray LW, Richardson JS, Richardson DC. 2010. MolProbity: all-atom structure validation for macromolecular crystallography. Acta Crystallogr D Biol Crystallogr 66:12-21.

53. Potterton L, McNicholas S, Krissinel E, Gruber J, Cowtan K, Emsley P, Murshudov GN, Cohen S, Perrakis A, Noble M. 2004. Developments in the CCP4 molecular-graphics project. Acta Crystallogr D Biol Crystallogr 60:2288-94.

54. Krissinel E. 2012. Enhanced fold recognition using efficient short fragment clustering. J Mol Biochem 1:76-85.

55. Evans P. 2006. Scaling and assessment of data quality. Acta Crystallogr D Biol Crystallogr 62:72-82.

56. Diederichs K, Karplus PA. 1997. Improved R-factors for diffraction data analysis in macromolecular crystallography. Nat Struct Biol 4:269-75.

57. Weiss MS. 2001. Global indicators of X-ray data quality. J Appl Crystallogr 34:130-135.

58. Evans P. 2012. Resolving some old problems in protein crystallography. Science 336:986-7.

59. Karplus PA, Diederichs K. 2012. Linking crystallographic model and data quality. Science 336:1030-3. 


\section{FIGURE LEGENDS}

738 Figure 1. The SARS-CoV-2 Mac1 is a small domain within nsp3 and is highly conserved

739 between other human $\mathrm{CoV}$ Mac1 protein domains. (A) Cartoon Schematic of the SARS-CoV-2

740 non-structural protein 3. The conserved macrodomain, or Mac1, is highlighted in yellow. (B)

741 Sequence alignment of Mac1 from CoVs; SARS-CoV-2, SARS-CoV, MERS-CoV, and mouse

742 hepatitis virus (MHV), and from alphaviruses Venezuelan equine encephalitis virus (VEEV) and

743 sindbis virus (SINV), and hepatitis E virus (HEV). Sequences were aligned using the ClustalW

744 method from Clustal Omega online tool with manual adjustment. Identical residues are bolded,

745 shaded in grey, and marked with asterisks; semiconserved residues were shaded in grey and

746 marked with two dots (one change amongst all viruses) or one dot (2 changes or conserved

747 within CoV family).

748 Figure 2. Structure of SARS-CoV-2 Mac1 complexed with ADP-ribose. A) The structure was

749 rendered as a blend through model from the N-terminus (blue) to the C-terminus (red). B) The

750 structure was colored by secondary structure showing sheets (magenta) and helices (green). The

751 ADP-ribose is rendered as gray cylinders with oxygens and nitrogens colored red and blue,

752 respectively.

753 Figure 3. Binding mode of ADP-ribose in SARS-CoV-2 Mac1. A) Fo-Fc Polder omit map

754 (green mesh) contoured at $3 \sigma$. B) Hydrogen bond interactions (dashed lines) between ADP-

755 ribose and amino acids. C) Interactions with water molecules. Direct hydrogen bond interactions

756 are represented by dashed lines and water mediated contacts to amino acids are drawn as solid

757 lines.

758 Figure 4. Structural comparison of the SARS-CoV-2 Mac1 protein with the SARS-CoV and

759 MERS-CoV Mac1 proteins. A-B) Superposition of SARS-CoV-2 macrodomain (magenta) with 
coronavirus macrodomain structures. A) SARS-CoV Mac1 with ADP-ribose (gold) (2FAV) and

B) MERS-CoV Mac1 with ADP-ribose (teal) (5HOL). C-D) Superposition of SARS-CoV-2

762 Mac1 (magenta) with other coronavirus Mac1 structures highlighting the ADP-ribose binding

763 site. C) SARS-CoV (gold), D) MERS-CoV (teal). The ADP-ribose molecules are colored gray

764 for SARS-CoV-2 Mac1 (A-D) and are rendered as green cylinders for SARS-CoV Mac1 (panel

765 A,C) and MERS-CoV Mac1 (panel B,D).

766 Figure 5. Human CoVs bind to ADP-ribose with similar affinity. A-B) ADP-ribose binding of

767 human Mdo2 and SARS-CoV, MERS-CoV, and SARS-CoV-2 Mac1 proteins by ITC. Images in

768 (A) are of one experiment representative of at least 2 independent experiments. Data in (B)

769 represent the combined averages of multiple independent experiments for each protein. Mdo2

$770 \mathrm{n}=2$; SARS-CoV n=5; MERS-CoV n=6; SARS-CoV-2 n=2.

771 Figure 6. Coronavirus Mac1 proteins are ADP-ribosylhydrolases. A) The SARS-CoV-2

772 macrodomain was incubated with MARylated PARP10 CD in vitro at equimolar ratios $(1 \mu \mathrm{M})$

773 for the indicated times at $37^{\circ} \mathrm{C}$. ADP-ribosylated PARP10 CD was detected by immunoblot (IB)

774 with anti-ADP-ribose binding reagent (Millipore-Sigma MAB1076). Total PARP10 CD and

775 macrodomain protein levels were determined by Coomassie Blue (CB) staining. PARP10 CD

776 incubated alone at $37^{\circ} \mathrm{C}$ was stopped at 0 or 60 minutes. B) The level of de-MARylation was

777 measured by quantifying band intensity using Image J software. Intensity values were plotted

778 and fit to a non-linear regression curve with error bars representing standard deviation. Results in

779 A are representative experiments of two independent experiments and data in $\mathbf{B}$ represent the

780 combined results of the two independent experiments. C) The Mdo2, MERS-CoV, SARS-CoV,

781 and SARS-CoV-2 macrodomains were incubated with MARylated PARP10 CD in vitro at the

782 following ratios of [substrate]:[Mac1]: 1:1 $(1 \mu \mathrm{M}), 5: 1(500 \mathrm{nM}, 100 \mathrm{nM})$, or 10:1 $(1 \mu \mathrm{M}, 100$ 
$\mathrm{nM}$ ) for the indicated times at $37^{\circ} \mathrm{C}$. ADP-ribosylated PARP10 CD was detected as described

784 above, and total PARP10 CD and macrodomain protein levels were determine by Coomassie

785 Blue (Fig. S6). D) Time-dependent substrate concentrations were determined by quantifying

786 band intensity using Image Studio software. The data were then analyzed using Mathematica 12,

787 as described in Methods, to determine the initial rate $(k)$ of substrate decay. Results in $\mathbf{C}$ are

788 representative experiments of three independent experiments and data in $\mathbf{D}$ represent the

789 combined results of the three independent experiments.

790 Fig. 7. Coronavirus Mac1 proteins do not hydrolyze PAR. PAR hydrolase assays were performed

791 with PARP1 either extensively poly-ADP-ribosylated $\left(500 \mu \mathrm{M} \mathrm{NAD}^{+}\right)$or partially poly-ADP-

792 ribosylated $\left(5 \mu \mathrm{M} \mathrm{NAD}^{+}\right)$to produce oligo-ADP-ribose. Macrodomains were incubated with

793 both automodified PARP1 substrates for 1 hour. PAR was detected by immunoblot with the anti-

794 PAR antibody 96-10. PARG (catalytically active $60 \mathrm{kD}$ fragment) was used as a positive control.

795 The results are representative of 2 independent experiments.

796 Figure 8. Development of an ELISA assay to detect de-MARylation. A) Cartoon schematic of

797 the ELISA assay. ELISA plates pre-coated with glutathione and pre-blocked were used capture

798 GST-tagged PARP10 proteins, which was used as a substrate for de-MARylation. The removal

799 of MAR was detected by anti-MAR antibodies. B) MARylated PARP10 (MAR+) and non-

800 MARylated PARP10 (MAR-) with no SARS-CoV-2 Mac1 as controls were detected with anti-

801 mono-ADP-ribose binding reagent ( $\alpha$-MAR) (Millipore-Sigma MAB1076) or with anti-GST ( $\alpha$ -

802 GST) (Invitrogen, MA4-004). C) Starting at $12.5 \mathrm{nM}, 2$-fold serial dilutions of the SARS-CoV-2

803 Mac1 protein was incubated in individual wells with MARylated PARP10-CD for 60 min at

$80437^{\circ} \mathrm{C}$. The graph represents the combined results of 2 independent experiments. 


\section{SUPPLEMENTAL FIGURE LEGENDS}

807 Figure S1. Purification and crystallization of macrodomain proteins. A) Macrodomain proteins

808 were purified as described in Methods. Equimolar amounts of the recombinant proteins were run

809 on a polyacrylamide gel and visualized by Coomassie staining. B) Crystals of SARS-CoV-2

810 Mac1 obtained with Salt Rx HT E10 supplemented with 0.1 M NDSB-256.

811 Figure S2. Extended residues at the C-terminus of the SARS-CoV-2 Mac1 clashed with

812 symmetry related molecules. A) Comparison of the amino acid sequence of SARS-CoV-2 Mac1,

813 6W02 and 6WEY. B) Superposition of SARS-CoV-2 Mac1 (magenta) subunit B onto subunit A

814 of 6W02 reveals that the C-terminus would clash with symmetry related molecules (coral).

815 Figure S3. Comparison of the SARS-CoV-2 Mac1 protein with homologous structures. A-B)

816 Superposition of SARS-CoV-2 Mac1 (magenta) with other recently determined homologous

817 structures. A) SARS-CoV-2 Mac1 apo structure (6WEN), B) SARS-CoV-2 Mac1 complexed 818 with ADP-ribose (6W02). The ADP-ribose molecule is colored gray for SARS-CoV-2 and is

819 represented as green cylinders for 6W02 in panel B. C-D) Comparison of the residues in the

820 ADP-ribose binding site. C) SARS-CoV-2 Mac1 apo structure (blue, 6WEN), D) SARS-CoV-2

821 Mac1 complexed with ADP-ribose (green, 6W02). The ADP-ribose of SARS-CoV-2 is rendered

822 as gray cylinders, and is represented as green cylinders for 6W02 in panel B.

823 Figure S4. ADP-ribose binding of macrodomain proteins by DSF assay. The macrodomain

824 proteins $(10 \mu \mathrm{M})$ were incubated with increasing concentrations of ADP-ribose and measured by

825 DSF as described in Methods. Mdo2 n=4; SARS-CoV n=6; MERS-CoV n=5; SARS-CoV-2 n=3.

826 Figure S5. Affinity of ADP-ribose binding antibodies for ADP-ribosylated PARP10 CD.

827 MARylated PARP10 and non-MARylated PARP10 CD were detected by immunoblot (IB) with

828 anti-GST (Invitrogen, MA4-004), anti-ADP-ribose binding reagents: anti-MAR (Millipore- 
829 Sigma MAB1076), anti-PAR (Millipore-Sigma MABC547), and anti-MAR/PAR (Millipore-

830 Sigma MABE1075) antibodies.

831 Figure S6. MARylated PARP10 stability over time. The presence of mono-ADP-ribose of

832 automodified PARP10 without any macrodomain was detected at 6 time points by immunoblot

833 analysis with the anti-GST (Invitrogen, MA4-004) and anti-ADP-ribose binding reagent anti-

834 MAR (Millipore-Sigma MAB1076).

835 Figure S7. The CoVs and human Mdo2 macrodomain proteins were incubated with MARylated

836 PARP10 CD in vitro for the indicated times at $37^{\circ} \mathrm{C}$. Total PARP10 CD and macrodomain

837 protein levels were determined by Coomassie Blue (CB) staining. Results showone experiment

838 of three independent experiments.

839 Figure S8. Differential PARylation of PARP1 by varying concentrations of NAD ${ }^{+}$. Recombinant

840 human PARP1 was automodified in a reaction buffer supplemented with increasing

841 concentrations of $\mathrm{NAD}^{+}$to generate substrates for the PAR hydrolase assays. PAR was detected

842 by immunoblot analysis of reaction products with the anti-PAR antibody 96-10. 
A

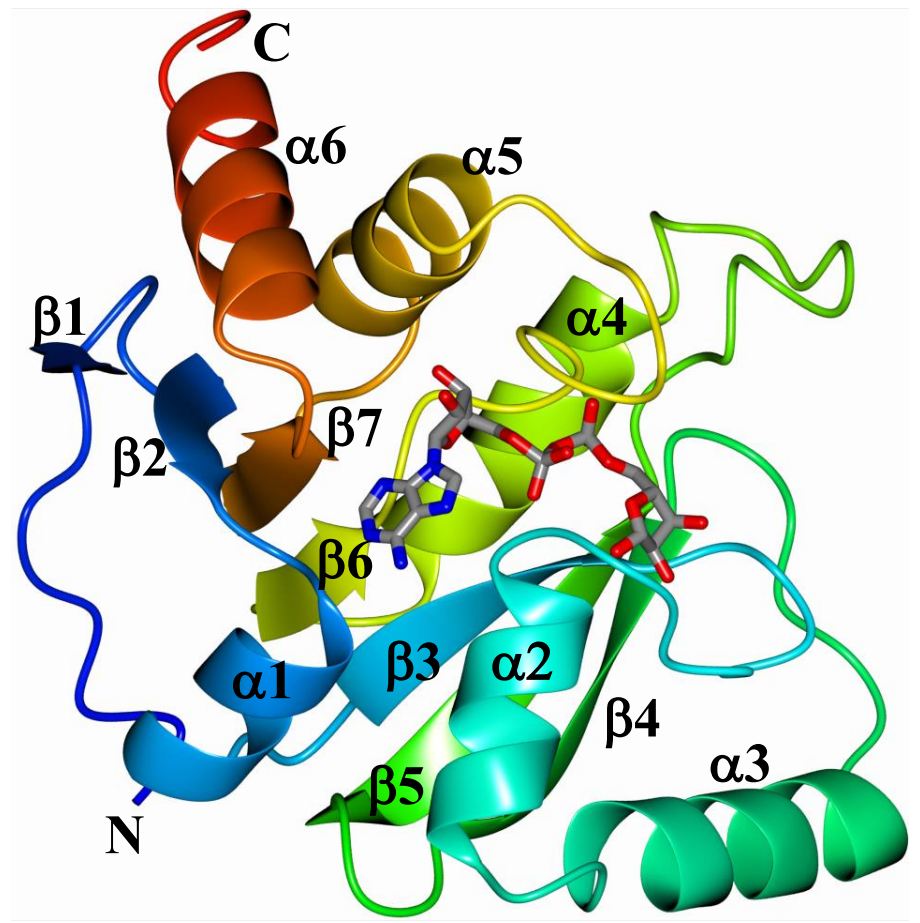

及1: L10-K11

及2: V16-A21

$\alpha 1$ : I23-V30

B3: V34-A39

$\alpha 2$ : V49-T57

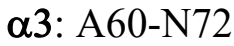

B4: S79-G85

B5: A89-V96

$\alpha 4:$ L108-Q118

及6: V121-A124

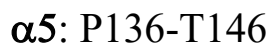

及7: N150-V155

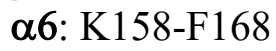

B

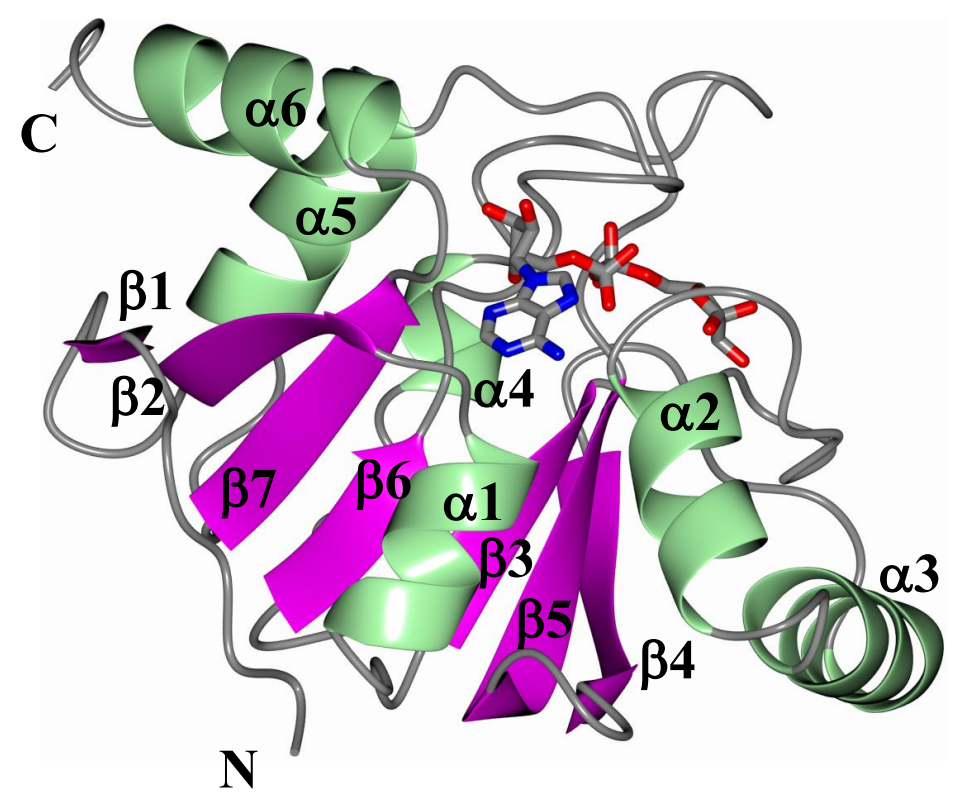



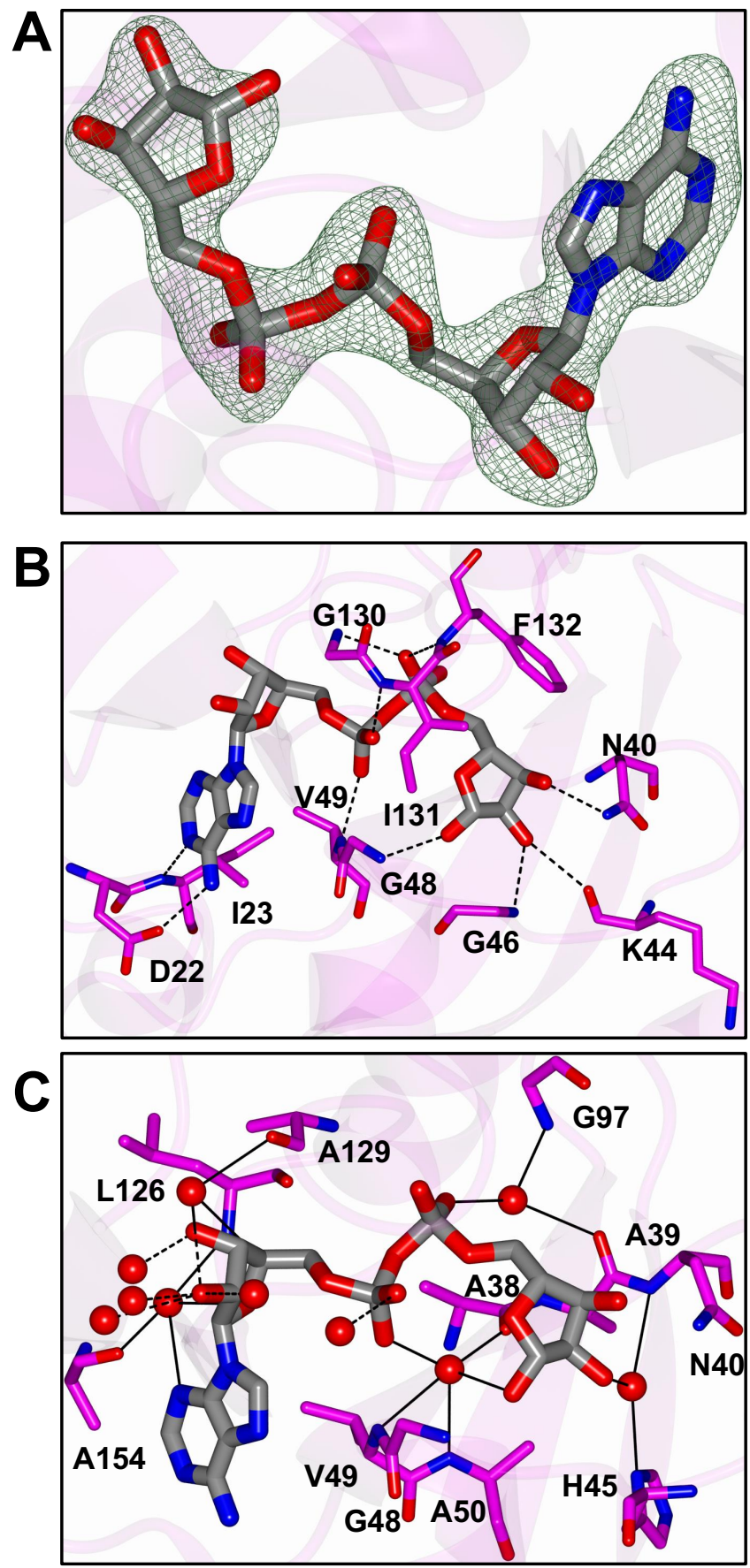
A

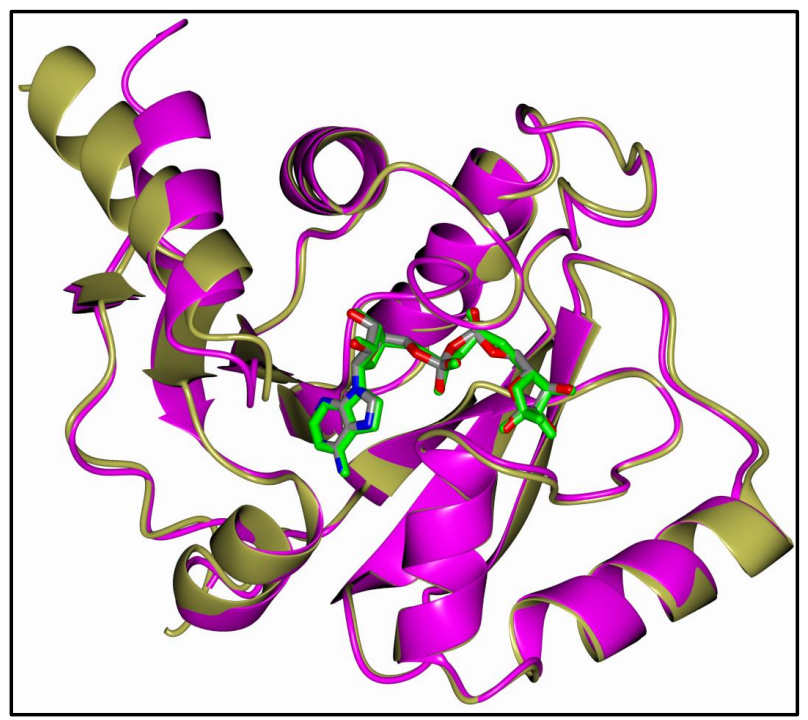

\section{C}

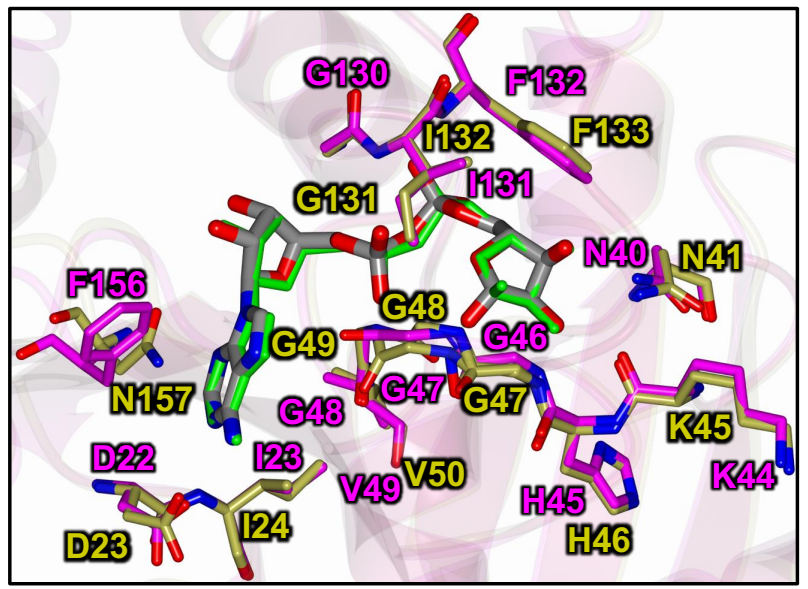

B

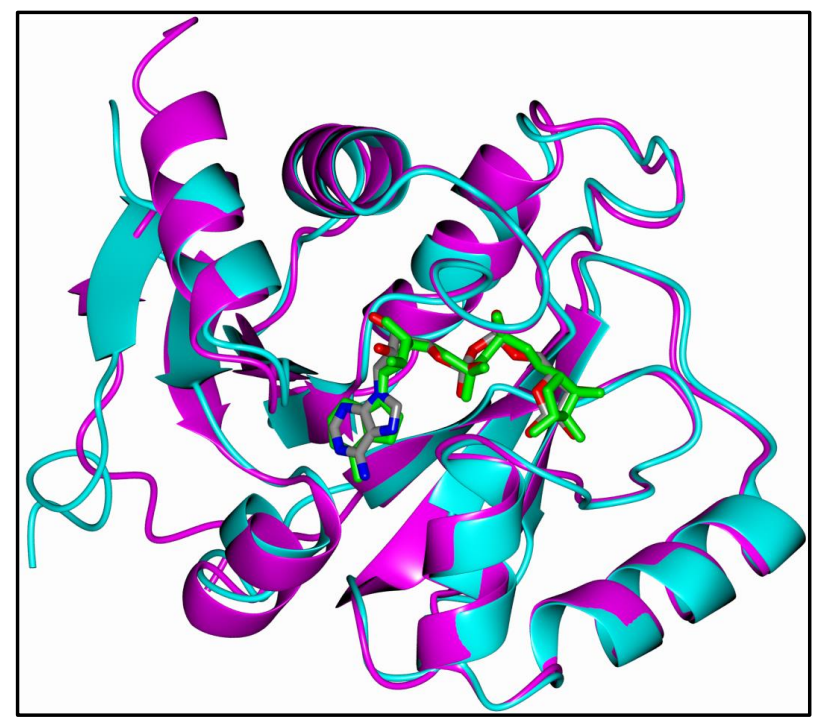

D

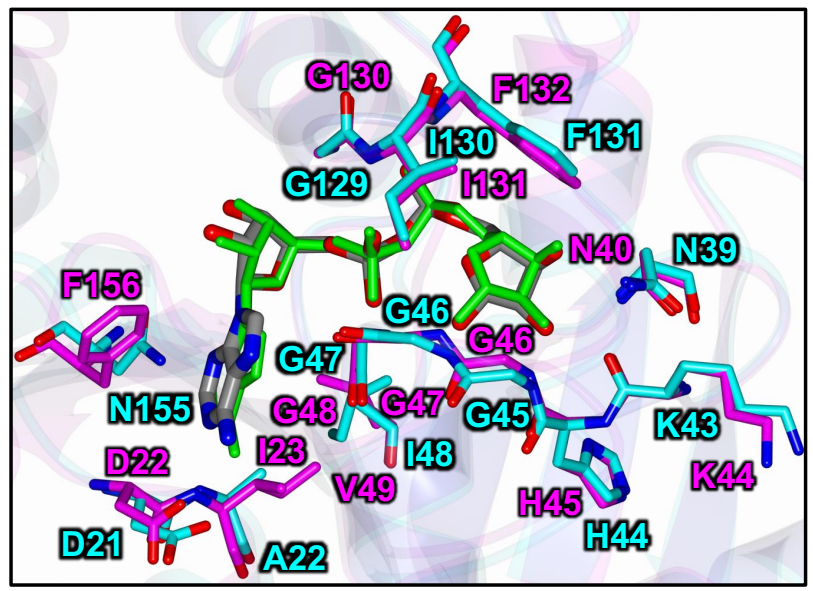


A
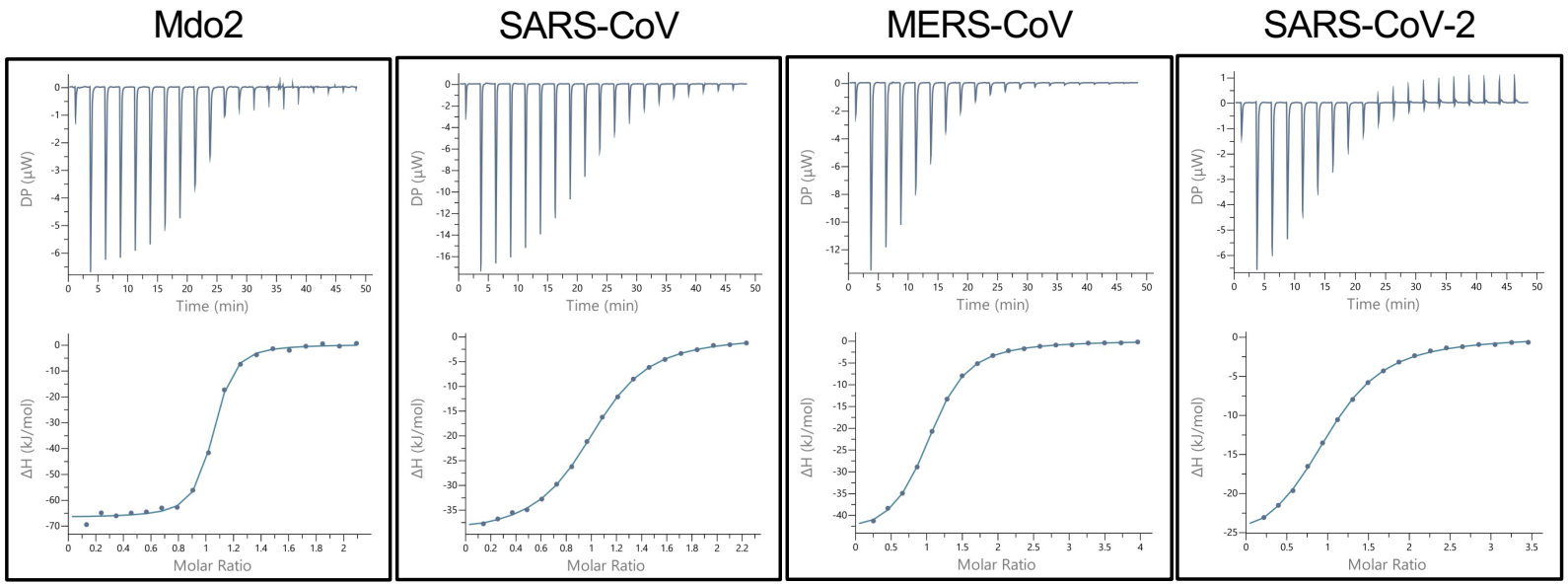

B

\begin{tabular}{|ccccc|}
\hline Macrodomain & $\begin{array}{c}\text { Stoichiometry } \\
(\mathbf{N})\end{array}$ & $\begin{array}{c}\mathbf{K d} \\
(\boldsymbol{\mu} \mathbf{M})\end{array}$ & $\begin{array}{c}\Delta \mathbf{H} \\
(\mathbf{k c a l} / \mathbf{m o l})\end{array}$ & $\begin{array}{c}\Delta \mathbf{G} \\
(\mathbf{k c a l} / \mathbf{m o l})\end{array}$ \\
\hline Mdo2 & $0.92 \pm 0.01$ & $0.24 \pm 0.02$ & $-66 \pm 1$ & $-38 \pm 2$ \\
SARS-CoV & $0.89 \pm 0.04$ & $10.8 \pm 1.7$ & $-40 \pm 1.2$ & $-28 \pm 0.4$ \\
MERS-CoV & $0.97 \pm 0.04$ & $7.9 \pm 0.15$ & $-47 \pm 3$ & $-29 \pm 0.4$ \\
SARS-CoV-2 & $1.14 \pm 0.06$ & $16.8 \pm 0.04$ & $-28 \pm 0.1$ & $-27 \pm 0.1$ \\
\hline
\end{tabular}


A

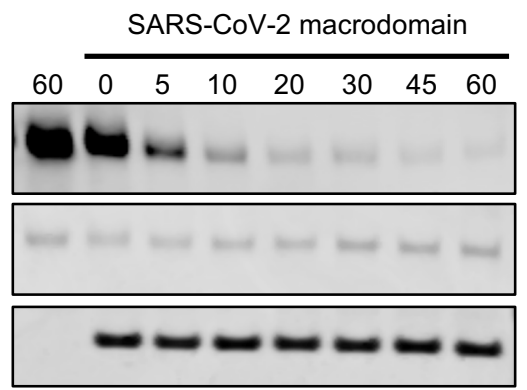

B

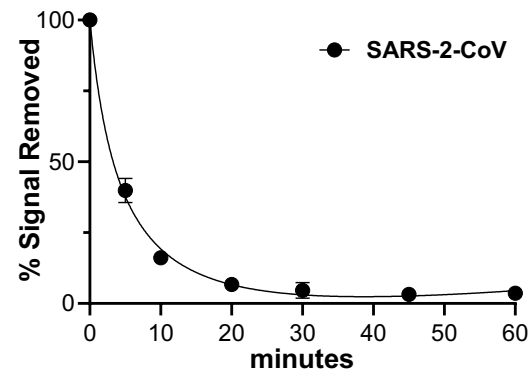

C Ratio

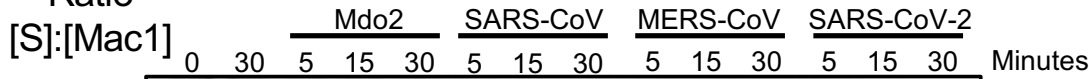

1:1

IB: $\alpha$-ADP-ribose

CB: PARP10 CD

CB: macrodomain WB: $\alpha$-ADP-ribose (MAR)

Mdo2 MERS-CoV

SARS-CoV

SARS-CoV-2

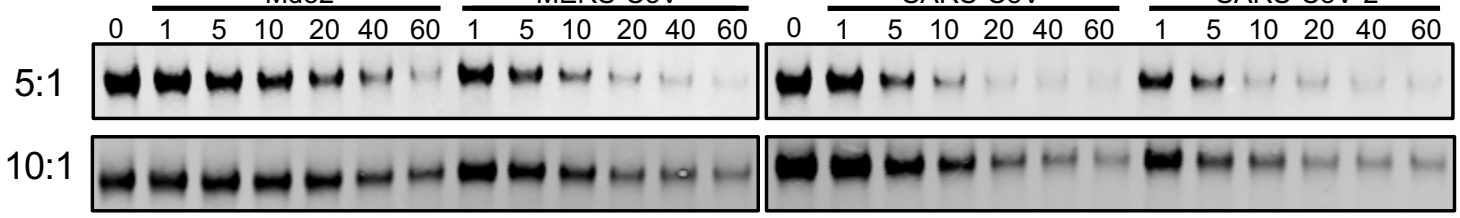
WB: $\alpha-M A R$ WB: $\alpha-M A R$

D Ratio [S]:[Mac1]

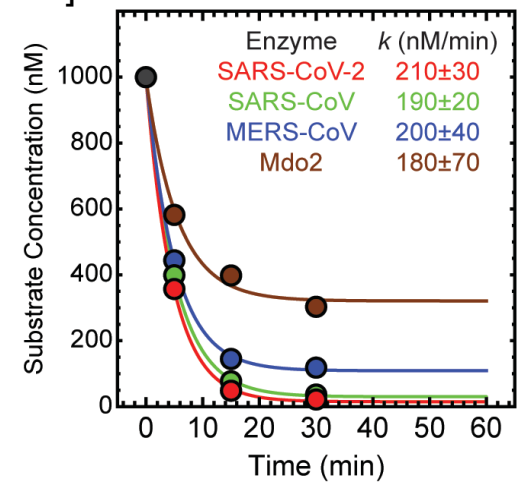

5:1

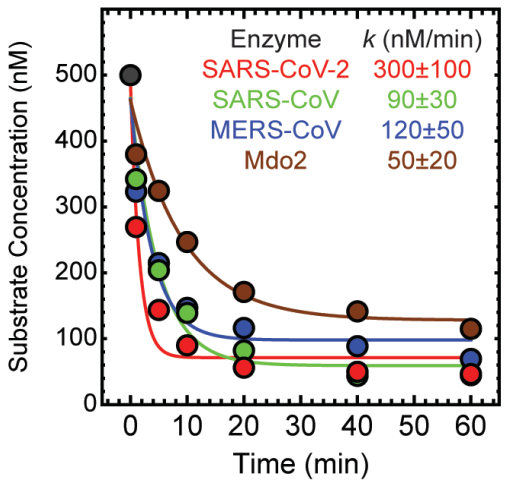

10:1

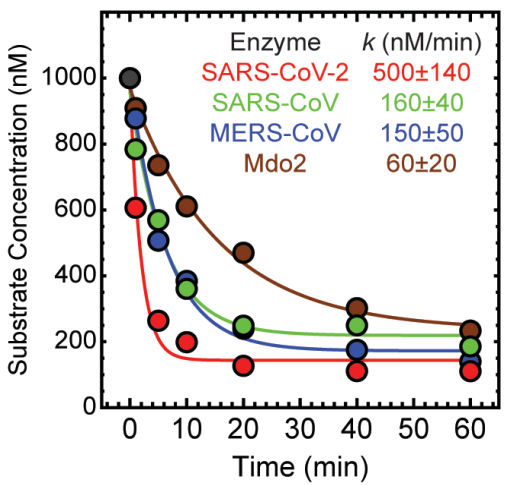




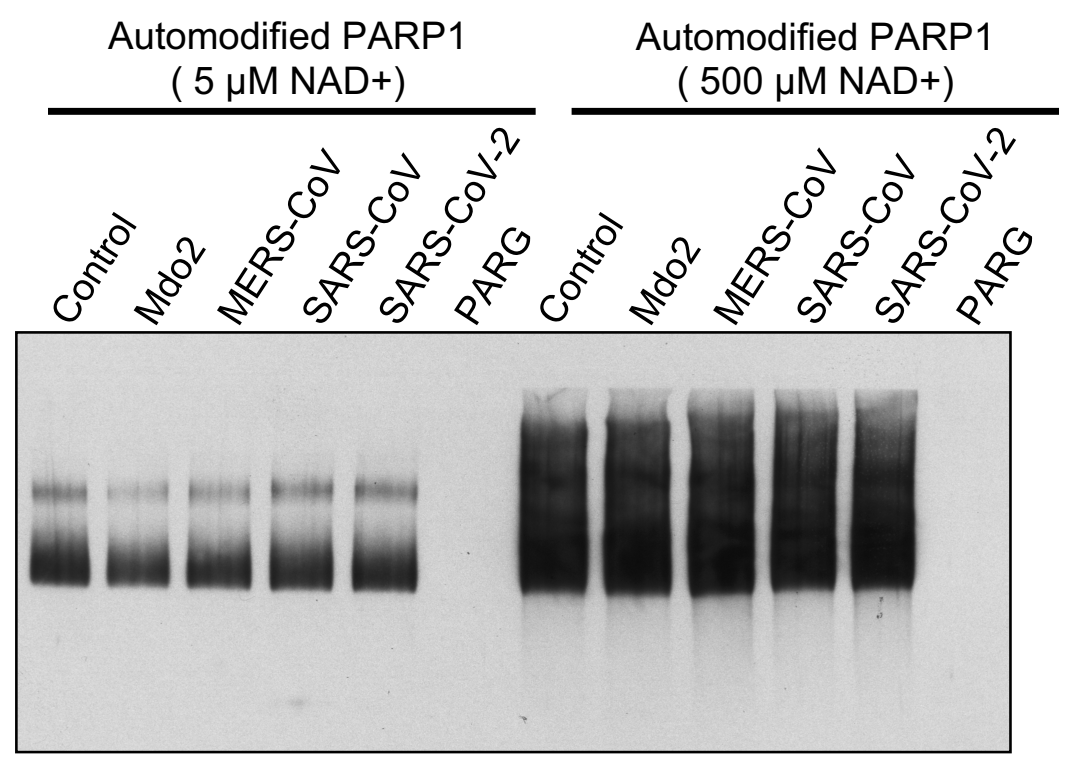




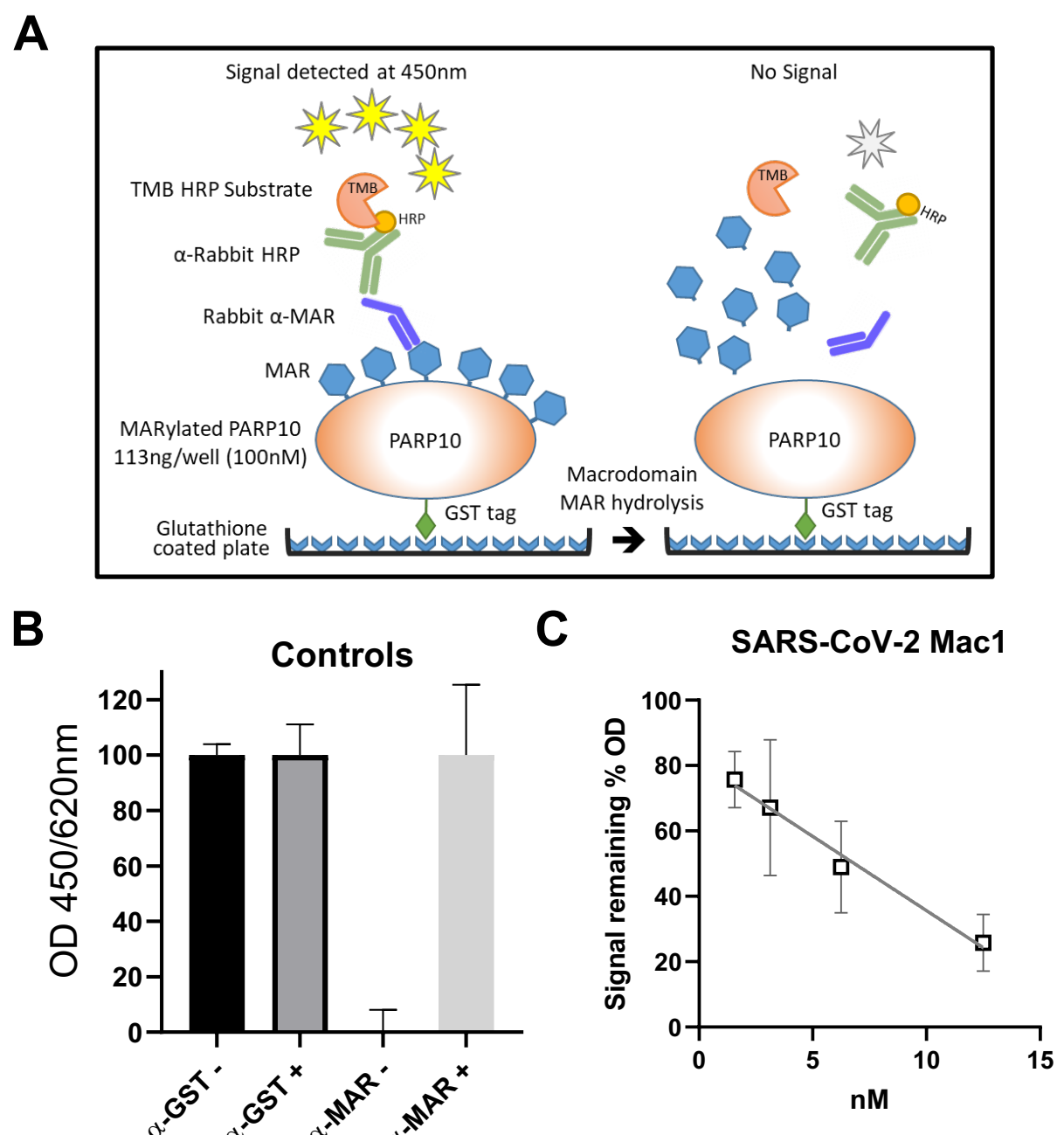

